\title{
USP11-dependent selective cIAP2 deubiquitylation and stabilization determine sensitivity to Smac mimetics
}

\author{
E-W Lee ${ }^{1}$, D Seong ${ }^{1}$, J Seo ${ }^{1}$, M Jeong ${ }^{1}$, H-K Lee ${ }^{1}$ and J Song ${ }^{\star, 1}$
}

Given their crucial role in apoptosis suppression, inhibitor of apoptosis proteins (IAPs) have recently become attractive targets for cancer therapy. Here, we report that cellular IAP2 (cIAP2) is specifically stabilized in several cancer cell lines, leading to resistance to Smac mimetics, such as BV6 and birinapant. In particular, our results showed that cIAP2 depletion, but not cIAP1 depletion, sensitized cancer cells to Smac mimetic-induced apoptosis. Ubiquitin-specific protease 11 (USP11) is a deubiquitylase that directly stabilizes cIAP2. USP11 overexpression is frequently found in colorectal cancer and melanoma and is correlated with poor survival. In our study, cancer cell lines expressing high levels of USP11 exhibited strong resistance to Smac mimetic-induced cIAP2 degradation. Furthermore, USP11 downregulation sensitized these cells to apoptosis induced by TRAIL and BV6 and suppressed tumor growth in a xenograft model. Finally, the TNF $\alpha /$ JNK pathway induced USP11 expression and maintained cIAP2 stability, suggesting an alternative TNF $\alpha$-dependent cell survival pathway. Collectively, our data suggest that USP11-stabilized cIAP2 may serve as a barrier against IAP-targeted clinical approaches.

Cell Death and Differentiation (2015) 22, 1463-1476; doi:10.1038/cdd.2014.234; published online 23 January 2015

Apoptosis is an inherent cell death program that is crucial for various physiological processes such as development, the immune response, and tumorigenesis. ${ }^{1}$ This process is finely tuned by numerous cellular signaling pathways involving hundreds of pro-apoptotic and anti-apoptotic factors., ${ }^{2,3}$ Inhibitor of apoptosis proteins (IAPs) are a conserved protein family containing the baculoviral IAP repeat (BIR) domain. ${ }^{4}$ There are eight human IAP proteins, including cellular IAP1 (cIAP1/BIRC2), clAP2/BIRC3, X chromosome-linked IAP (XIAP/BIRC4), and melanoma IAP (ML-IAP/BIRC7). ${ }^{5}$ IAPs such as XIAP can exert their anti-apoptotic function through the BIR domain, which directly interacts with caspases. ${ }^{5}$ In addition, several IAPs contain a RING domain with E3 ubiquitin ligase activities, which are crucial for apoptosis suppression. In particular, the E3 ligase activities of clAP1/2 are necessary to regulate tumor necrosis factor receptor (TNFR) signaling. ${ }^{6}$ Upon TNFR activation, clAP $1 / 2$ is recruited to TNFR through TNFa receptor-associated factor 2 (TRAF2), leading to K63-linked polyubiquitylation of receptor interacting protein kinase 1 (RIPK1), which is essential for NF-KBmediated cell survival. ${ }^{7}$ The lack of RIPK1 polyubiquitylation via cIAP1/2 depletion or the presence of CYLD deubiquitylase triggers TNFR complex lla formation, thereby inducing caspase-8-dependent apoptosis. ${ }^{8}$ In addition, clAP1/2 prevents the formation of the RIPK1-containing death complex ripoptosome in response to several stimuli including CD95, TNF $\alpha$-related apoptosis-inducing ligand (TRAIL), genotoxic stress, and Toll-like receptor (TLR) activation. ${ }^{9-13}$
IAPs are frequently overexpressed in various human cancers, and their expression is associated with chemoresistance and poor clinical outcome. ${ }^{6}$ Therefore, inhibiting IAP function is an attractive strategy to treat cancer through the induction of apoptosis. ${ }^{5,14}$ Upon apoptotic stimuli, IAPs are inhibited by the second mitochondria-derived activator of caspases (Smac), ${ }^{5}$ and this discovery led to the development of Smac mimetic peptides using the IAP binding motif containing four amino acids (Ala-Val-Pro-lle). These peptides were shown to sensitize cells to apoptotic stimuli and efficiently suppress tumor growth in a xenograft model. ${ }^{15,16}$ Subsequently, a number of small-molecule compounds mimicking the Smac mimetic peptide (Smac mimetics) were developed with improved pharmacological properties and IAP-binding affinity. Interestingly, Smac mimetics, such as BV6 and compound $A$, were found to induce autoubiquitylation and degradation of $\operatorname{clAP} 1 / 2 .{ }^{17,18}$ Furthermore, ClAP1/2 depletion with Smac mimetics activates the non-canonical NF- $\kappa B$ pathway to induce autocrine TNF $a$ production, which is essential for Smac mimetic-induced apoptotic cell death. ${ }^{18,19}$

Because CIAP1 and clAP2 show functional redundancy in TNF $a$-mediated survival, the depletion of both proteins is usually required for effective induction of cell death upon TNF $a$ treatment. ${ }^{20,21}$ However, there are several reports showing that ClAP2 expression, but not ClAP1 expression, renders cells resistant to Smac mimetic-induced cell death. ${ }^{20,21}$ For example, clAP2 upregulation via phosphoinositide 3-kinase (PI3K) upon compound 3 treatment in certain cell lines was shown to facilitate apoptosis evasion. ${ }^{22}$ In addition, treatment

\footnotetext{
${ }^{1}$ Department of Biochemistry, College of Life Science and Biotechnology, Yonsei University, Seoul 120-749, Korea

*Corresponding author: J Song, Department of Biochemistry, Yonsei University, Yonsei-ro 50, Seodaemun-gu, Seoul 120-749, Korea. Tel: +82 221235695 ; Fax: +82 2362 9897; E-mail: js0678@yonsei.ac.kr

Abbreviations: IAP, inhibitor of apoptosis; cIAP2, cellular IAP2; BIR, baculoviral IAP repeat; XIAP, X chromosome-linked IAP; ML-IAP, melanoma IAP; USP11, ubiquitinspecific protease 11; TNFR, tumor necrosis factor receptor; TRAF2, TNF $\alpha$ receptor-associated factor 2; RIPK1, receptor interacting protein kinase; TRAIL, TNF $\alpha$-related apoptosis-inducing ligand; TLR, Toll-like receptor; Smac, second mitochondria-derived activator of caspases; PI3K, phosphoinositide 3-kinase; TGF $\beta$, transforming growth factor-beta
}

Received 20.10.14; revised 08.12.14; accepted 10.12.14; Edited by D Vaux; published online 23.1.15 
with compounds $\mathrm{A}$ and $\mathrm{C}$ led to clAP1 dimerization, without clAP2 dimerization, resulting in the autoubiquitylation and subsequent degradation of clAP1. These findings may explain why clAP1 is degraded more efficiently than clAP2 upon treatment with Smac mimetics. ${ }^{23}$ Alternatively, because clAP2 degradation requires clAP1, clAP2 may become more stable when clAP1 is depleted using Smac mimetics. ${ }^{24}$ Direct clAP deubiquitylation by OTUB1 or USP19 has been suggested to be responsible for clAP stabilization; ${ }^{25,26}$ however, these previous studies did not focus on the difference in stabilization between clAP1 and clAP2 and only provided general deubiquitylation-dependent mechanisms. ${ }^{25,26}$

While several studies have supported hypotheses for how clAP2 survives in the presence of Smac mimetics, numerous independent studies have also shown that clAP2 can be efficiently degraded by Smac mimetics in various cell lines. ${ }^{27-32}$ These observations suggest the existence of other factors that specifically regulate cIAP2 stability upon Smac mimetic treatment. In this study, we propose a new mechanism involving USP11-mediated cIAP2 regulation. We found that the differential destabilization of clAP1 and clAP2 is dependent on the presence of the cIAP2-specific deubiquitylase USP11. Mechanistically, USP11 can protect clAP2 from Smac mimetic-mediated degradation, rendering cell lines with high USP11 expression unresponsive to Smac mimetic treatment. However, USP11 downregulation sensitized these cells to TNFa- or TRAIL-induced apoptosis in the presence of Smac mimetic and further suppressed tumor growth in a xenograft model. Corroborating these data, USP11 overexpression was observed in colon cancer and melanoma patients with poor clinical outcome. Finally, the TNFa/c-Jun $\mathrm{N}$-terminal kinase (JNK) pathway induced USP11 expression, which was necessary for clAP2 protein stabilization and its anti-apoptotic function. Thus, the identification of clAP2specific deubiquitylation indicates that more elaborate strategies should be developed for pharmaceutical therapies targeting clAPs.

\section{Results}

TNFa stimulation induces cIAP2 expression and renders cells resistant to Smac mimetic-induced apoptotic cell death. Smac mimetics such as BV6 induce IAP autoubiquitylation and degradation, thereby sensitizing cancer cells to apoptotic stimuli. ${ }^{17,18}$ Consistently, we observed that CIAP1 and clAP2 showed similar sensitivities to BV6 in TNFa-treated HT-29 cells (Figures $1 \mathrm{a}$ and b). Interestingly, BV6-mediated clAP2 degradation was extensively protected in $\mathrm{H} 1299$ cells compared with clAP1 degradation in the presence or absence of TNFa treatment (Figures 1a-c). In contrast to clAP2, clAP1 expression was not affected by TNF $a$ stimulation and showed exhaustive destabilization after BV6 co-treatment (Figure 1c). It has previously been reported that several Smac mimetics can induce clAP2 expression in certain conditions. ${ }^{22,33}$ To test whether BV6 increased cIAP2 expression in our conditions, we stimulated cells with TNFa in the presence or absence of BV6. clAP2 induction following TNF $a$ treatment was not affected by BV6 treatment, excluding the possibility of BV6 affecting clAP2 transcriptional levels
(Figure 1d). Finally, unlike clAP1, clAP2 induced by TNFa pretreatment in $\mathrm{H} 1299$ cells was resistant to BV6 and cycloheximide $(\mathrm{CHX})$ treatment, suggesting that clAP2 was indeed protected from protein degradation (Figure 1e). H1299 cells stimulated with TNFa and BV6 exhibited slight activation of caspase- 8 and -3 , possibly due to the comparable expression and stabilization of clAP2 (Figure 1f). Furthermore, clAP2 knockdown, but not clAP1 knockdown, facilitated caspase activation and subsequent TNFa/BV6induced cell death (Figures $1 \mathrm{f}$ and $\mathrm{g}$ ). We further tested an additional Smac mimetic, birinapant, which was recently reported to induce efficient degradation of both CIAP1 and clAP2. ${ }^{28}$ Similar to BV6, birinapant also exhibited limited clAP2 degradation in H1299 cells, and clAP2 depletion, but not clAP1 depletion, decreased H1299 cell viability upon TNFa and birinapant treatment (Supplementary Figures S1a and b). Overall, these observations suggest that clAP2 induction and stabilization by TNFa may inhibit Smac mimetic-induced apoptosis in certain cancer cell lines.

USP11, a novel cIAP2 deubiquitylating enzyme, is responsible for cIAP2 stabilization. clAP2's resistance to Smac mimetic-induced degradation indicates that deubiquitylating enzymes (DUBs) (or deubiquitylase) may inhibit clAP2 ubiquitylation-mediated degradation. Sixty-seven DUBs were tested in a screen for a clAP2 deubiquitylase. Several DUBs, including USP11, USP26, USP29, USP37, OTUD1, OTUD7B, and DUB3, increased clAP2 expression (Figure 2a; Supplementary Figure S2); however, despite their effects on clAP2 protein levels, only USP11 and DUB3 effectively reduced clAP2 ubiquitylation (Figures $2 b$ and $c$ ). Among these DUBs, we focused on USP11 because it is known to regulate various signaling pathways involved in cell survival, including TNF $\alpha$, TGF $\beta$, and Notch signaling. Protein binding analyses showed that endogenous USP11 interacted with endogenous clAP2, and their interaction was enhanced upon TNFa treatment (Figure 2d). We further demonstrated this protein interaction using ectopically expressed or recombinant proteins (Figures $2 e$ and $f$ ).

To further analyze the roles of USP11 in clAP2 regulation, wild-type (WT) USP11 and a catalytically inactive C318S mutant (MT) were employed. While WT and MT USP11 bound to clAP2, only WT USP11 led to increased clAP2 levels (Figures $2 \mathrm{e}$ and $3 \mathrm{a}$ ). Inhibition of proteasomal degradation by MG132 notably stabilized clAP2, whereas USP11 did not further stabilize clAP2 upon MG132 treatment, suggesting that USP11 rescued clAP2 from proteasomal degradation (Figure 3b). Moreover, the clAP2 half-life was significantly delayed from 3 to $9 \mathrm{~h}$ in the presence of USP11 (Figure 3c), and ubiquitylation analysis suggested that WT USP11, but not MT USP11, decreased cIAP2 ubiquitylation (Figure 3d). In addition, USP11 almost completely removed the ubiquitin chain from ubiquitylated-clAP2, resulting in free cIAP2 accumulation in vitro (Figure $3 e$ ). These results clearly supported the notion that USP11 is a direct cIAP2 DUB. Finally, ectopic USP11 expression abrogated exogenous clAP2 degradation by BV6 (Figure 3f), suggesting that USP11 is a bona fide cIAP2 DUB that protects clAP2 against proteasomal degradation. 
a

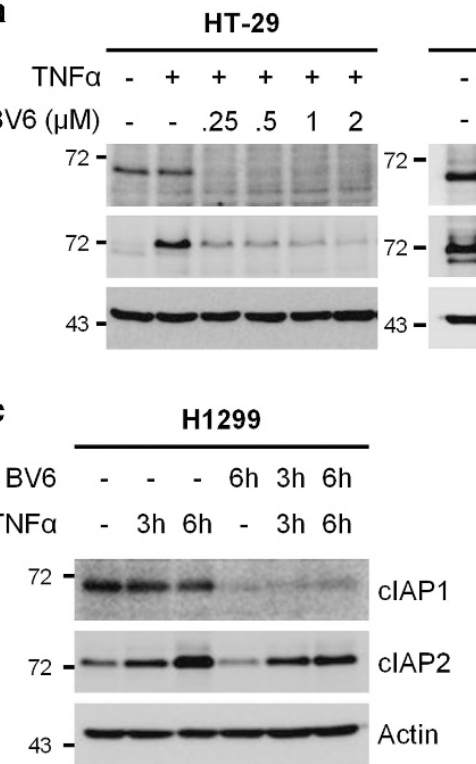

H1299

- - - - -

$\begin{array}{rrrr}-.25 & .5 & 1 & 2\end{array}$

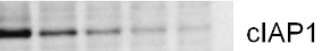

부ㄴㅡㅔ $-\operatorname{clAP} 2$

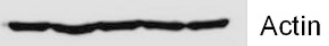

b

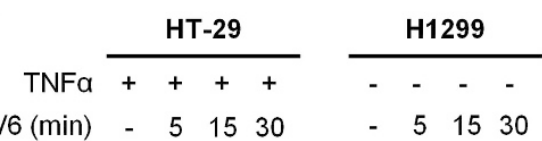

BV6 (min) - 51530
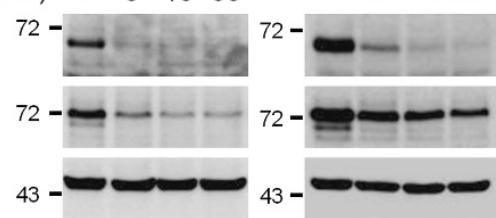

ClAP1

clAP2

Actin

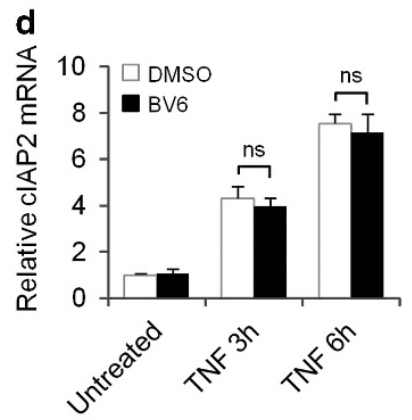

e

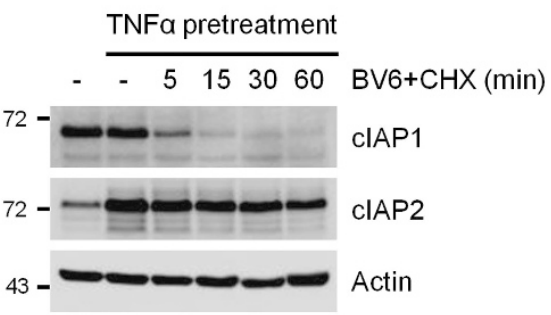

f
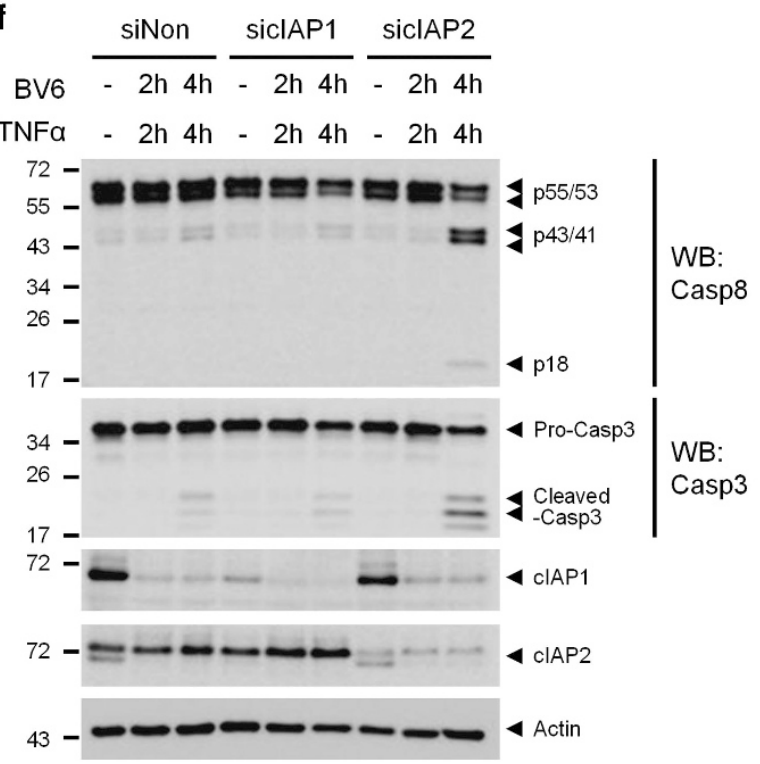

g $\square$ siNON

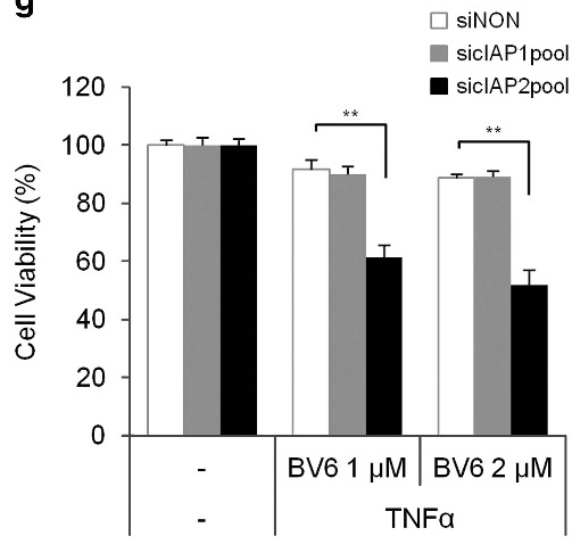

Figure 1 Inefficient cIAP2 degradation upon BV6 treatment prevents caspase-dependent apoptosis. (a) HT-29 cells were pretreated with $5 \mathrm{ng} / \mathrm{ml}$ TNF $\alpha$ for $12 \mathrm{~h}$ and treated with increasing concentrations of BV6 for $30 \mathrm{~min}$. H1299 cells were treated with BV6 in the absence of TNF $\alpha$ as indicated. clAP1 and clAP2 protein levels were determined by WB. (b) H1299 and TNF $\alpha$-treated HT-29 cells were treated with $1 \mu \mathrm{M} \mathrm{BV} 6$ for the indicated time periods, and the protein levels were determined by WB. (c and d) H1299 cells were treated with $20 \mathrm{ng} / \mathrm{ml} \mathrm{TNF} \alpha$ and $1 \mu \mathrm{M} \mathrm{BV}$, as indicated. clAP1/2 protein levels were determined by WB (c), and clAP1/2 mRNA levels were determined by quantitative reverse-transcriptase PCR (qRT-PCR) (d) (data represent the mean \pm S.D.; $n=3, \mathrm{n} . \mathrm{s}$. $=$ non-significant). (e) $\mathrm{H} 1299$ cells were pretreated with $20 \mathrm{ng} / \mathrm{ml} \mathrm{TNF} \alpha$ for $6 \mathrm{~h}$ and treated with $1 \mu \mathrm{M} \mathrm{BV6}$ in the presence of $50 \mu \mathrm{g} / \mathrm{ml} \mathrm{CHX}$. WB was performed to detect clAP1 and clAP2. (f) H1299 cells were transfected with $20 \mathrm{nM}$ of an siRNA pool against clAP1 or clAP2 and treated with $20 \mathrm{ng} / \mathrm{ml} \mathrm{TNF} \alpha$ and $1 \mu \mathrm{M} \mathrm{BV} 6$ for 2 or $4 \mathrm{~h}$. Caspase-8 and -3 activation was determined by WB. (g) siRNA-transfected H1299 cells were treated with TNF $\alpha$ and BV6 for $6 \mathrm{~h}$. Cell viability was determined by measuring ATP levels using the Cell Titer Glo Luminescent Cell Viability Assay Kit (data represent the mean \pm S.D.; $n=3$, $\left.{ }^{* *} P<0.01\right)$

USP11 inhibition decreases cIAP2 levels and sensitizes cells to apoptosis. We next tested whether USP11 is indeed involved in the regulation of clAP2 stability by performing knockdown experiments. USP11 depletion using two independent siRNAs or lentiviral shRNAs resulted in clAP2 downregulation in $\mathrm{H} 1299$ cells (Figure 4a; Supplementary Figure S3a). clAP2 levels also decreased upon USP11 depletion in HeLa and MDA-MB-231 cells, suggesting that USP11 is a general clAP2 regulator (Supplementary Figure 3b). Although clAP1 and clAP2 are highly homologous with redundant functions, USP11 did not regulate clAP1 levels even though there was a slight interaction between the two in vitro (Figure 4a; Supplementary Figures S3a and $\mathrm{c}$ ). Expression of other 
a

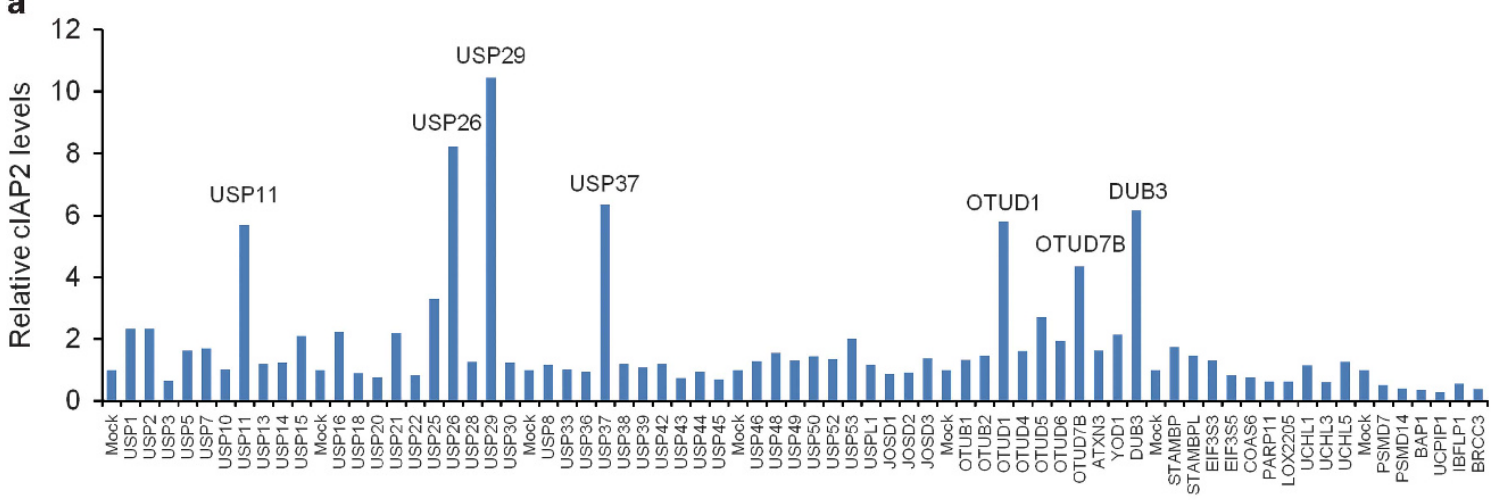

b

FLAG-HA-DUBS

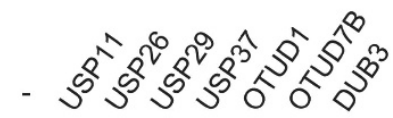

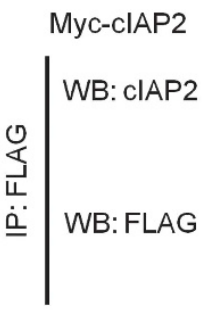

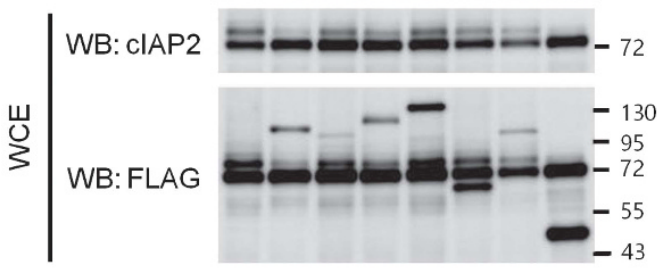

d

IP: IgG USP11 $5 \%$ Input

TNFa: $\frac{-8 \mathrm{~h}}{-\quad-8 \mathrm{~h}}$

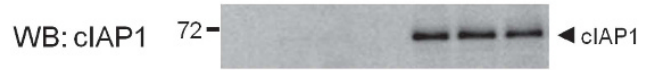

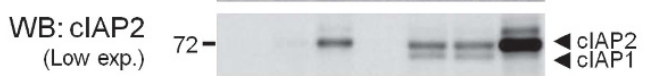

WB: ClAP2
(High exp.)

WB: USP11 ${ }^{130-},-\infty-\infty$ USP11

e

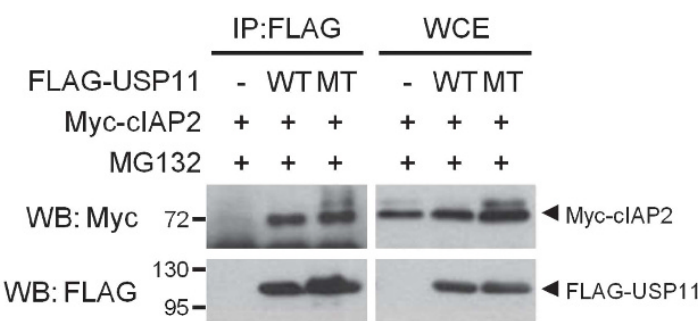

C

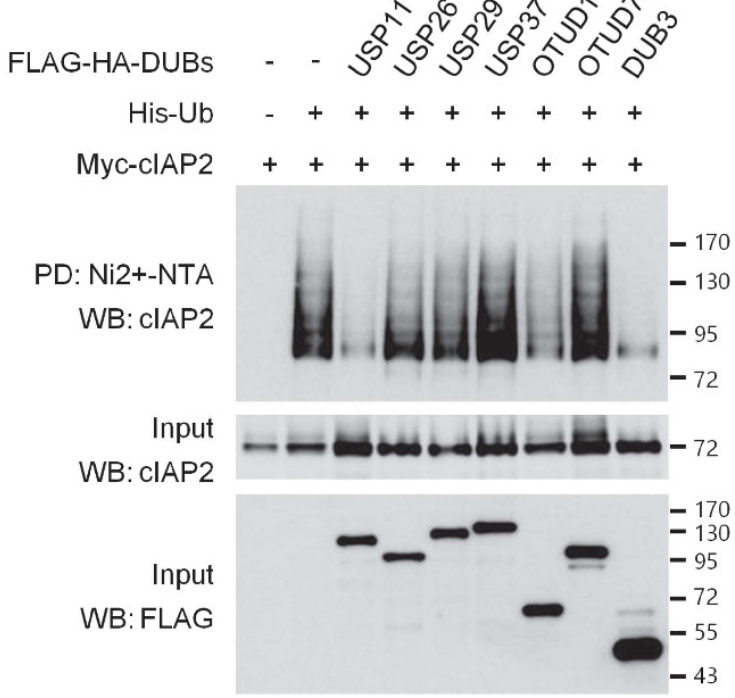

f

His-clAP2 + +

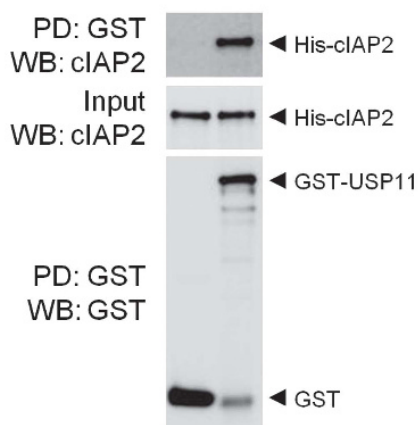

Figure 2 USP11 is a DUB that stabilizes cIAP2 via direct binding. (a) Relative cIAP2 protein levels normalized to 6xMyc in the presence of each DUB are shown in the graph. (b) 293FT cells, transfected with the indicated construct, were treated with $10 \mu \mathrm{M} \mathrm{MG132}$ for $6 \mathrm{~h}$. Cell lysates were immunoprecipitated with an anti-FLAG antibody, followed by WB. (c) 293FT cells were transfected with the indicated construct, and cIAP2 ubiquitylation was purified using Ni2 ${ }^{+}$-NTA beads and detected by WB. (d) Lysates of H1299 cells stimulated with or without TNF $\alpha$ were immunoprecipitated with an anti-USP11 antibody, followed by WB. (e) 293FT cells were transfected as indicated and treated with $10 \mu \mathrm{M}$ MG132 for $6 \mathrm{~h}$. Cell lysates were immunoprecipitated with an anti-FLAG antibody, followed by WB using an anti-Myc antibody. (f) Bacterially purified GST-USP11 was incubated with His-cIAP2 and pulled down with glutathione sepharose beads. USP11-bound cIAP2 was detected by WB using an anti-clAP2 antibody 


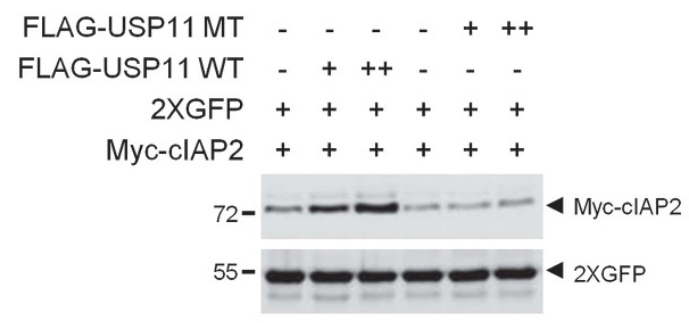

C

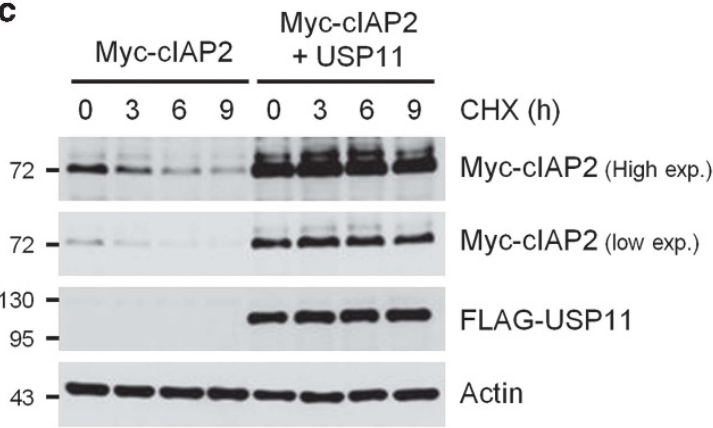

d

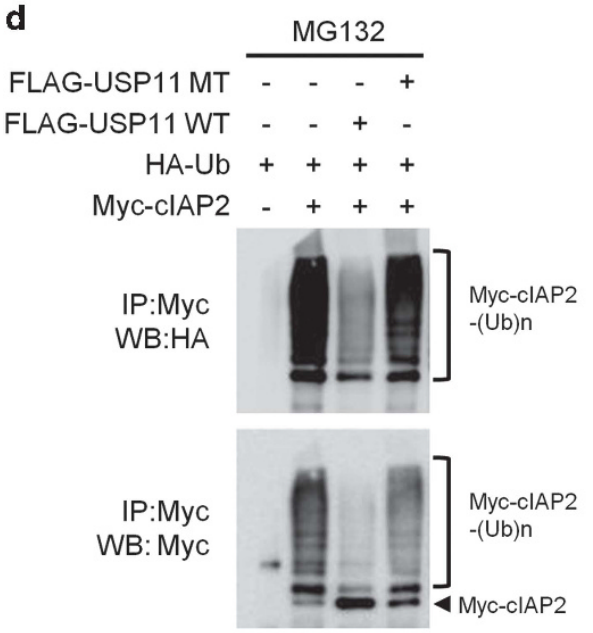

f

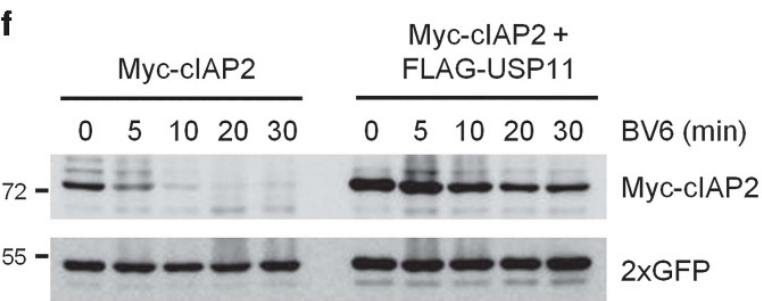

b
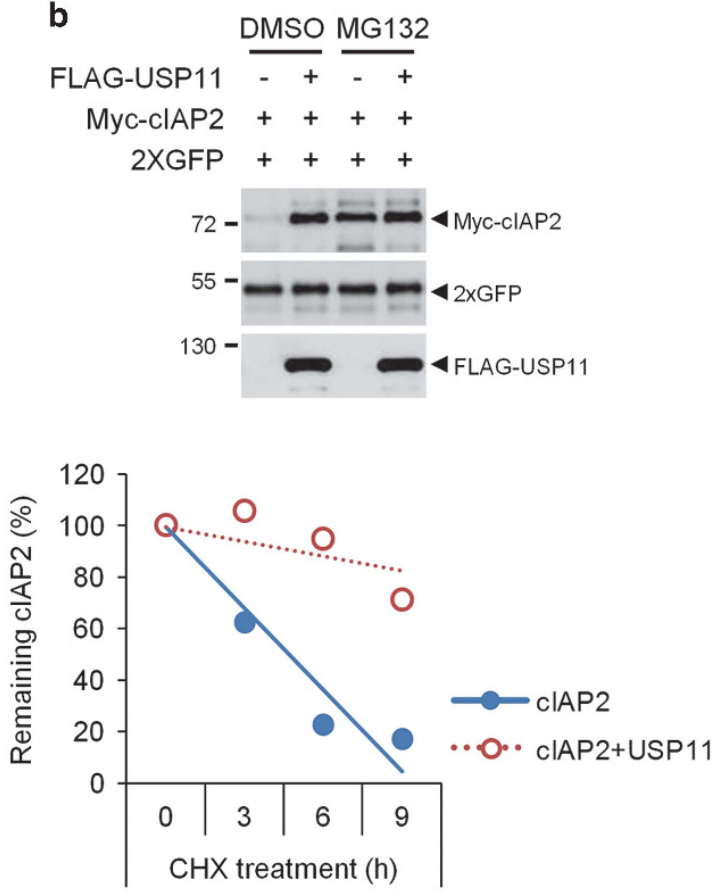

e

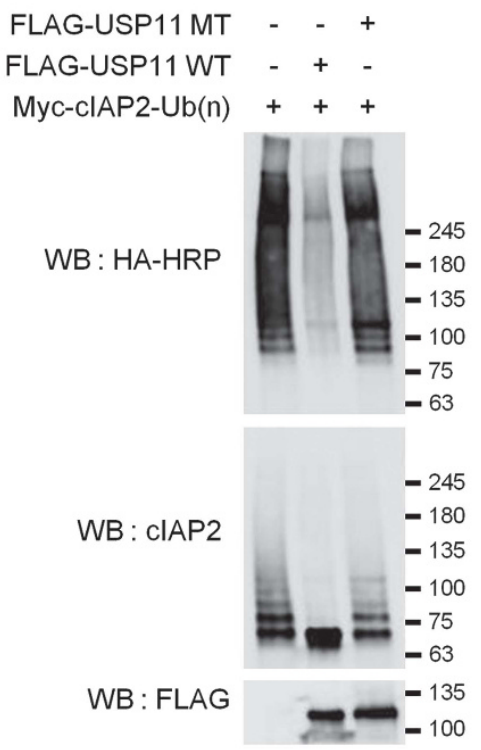

Figure 3 USP11 is a cIAP2-deubiquitylaing enzyme that stabilizes cIAP2. (a) 293FT cells were transfected with the plasmid expressing Myc-cIAP2 and increasing amounts of WT or catalytic inactive mutant (MT) FLAG-USP11. CIAP2 protein levels were determined by WB, and 2xGFP was used as a transfection control. (b) 293FT cells were transfected with clAP2-expressing plasmid in the presence or absence of USP11 and treated with $10 \mu \mathrm{M}$ MG132 for $6 \mathrm{~h}$. (c) 293FT cells were transfected with the indicated plasmid and treated with $50 \mu \mathrm{g} / \mathrm{ml} \mathrm{CHX.} \mathrm{Relative} \mathrm{amounts} \mathrm{of} \mathrm{Myc-clAP2} \mathrm{were} \mathrm{calculated} \mathrm{after} \mathrm{normalizing} \mathrm{to} \mathrm{actin,} \mathrm{and} \mathrm{are} \mathrm{shown} \mathrm{in} \mathrm{the} \mathrm{right} \mathrm{panel.} \mathrm{(d)} \mathrm{293FT} \mathrm{cells} \mathrm{were}$ transfected with the indicated plasmid and treated with MG132. Cells were lysed in 1\% SDS and immunoprecipitated with an anti-Myc antibody, followed by WB using an HRPconjugated anti-HA antibody. (e) Ubiquitylated cIAP2, purified by immunoprecipitation using HA-Ub, was incubated with FLAG-USP11 in the presence of ATP for $6 \mathrm{~h}$. The clAP2 ubiquitylation status was determined by WB using an anti-HA or anti-cIAP2 antibody. (f) 293FT cells were transfected with the cIAP2 expression vector with or without the FLAGUSP11 expression vector and treated with $2 \mu \mathrm{M}$ BV6 for the indicated time period 
IAP members including XIAP, ML-IAP, and Survivin did not change upon USP11 depletion, suggesting that USP11 specifically controls cIAP2 levels (Figure 4a). In addition,
clAP2 mRNA levels did not change after USP11 depletion, suggesting that USP11 does not regulate CIAP2 at the transcriptional level (Figure 4b). MG132 treatment effectively

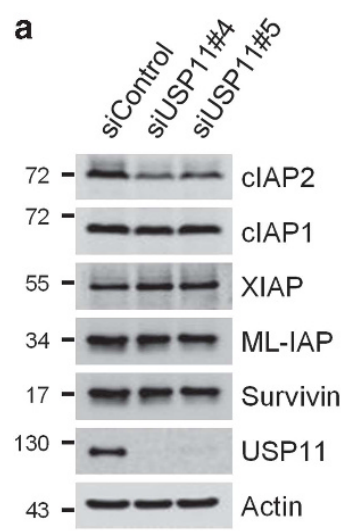

b

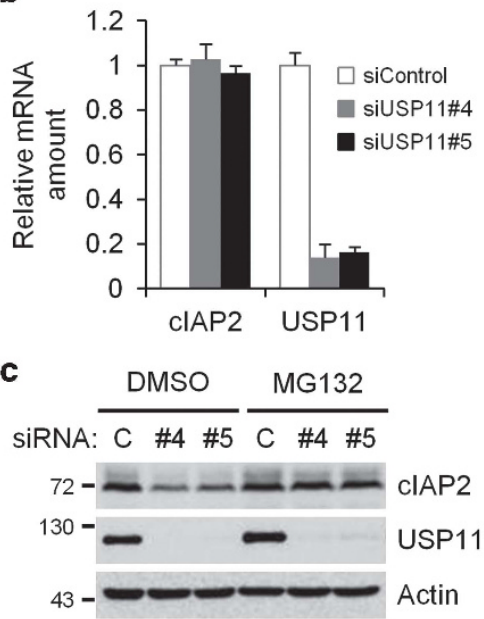

e

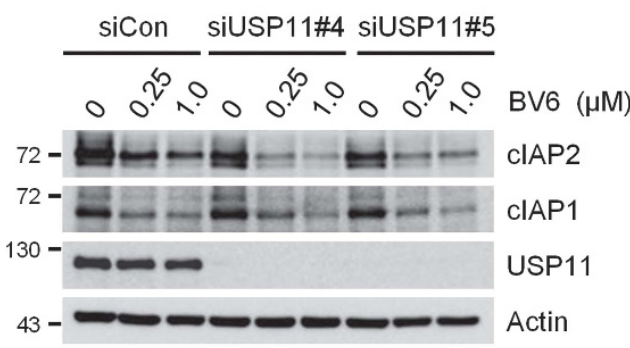

g TRAIL TRAIL TRAIL Untreated $10 \mathrm{ng} / \mathrm{mL}+\mathrm{BV} 6,0.5 \mu \mathrm{M}+\mathrm{BV} 6,2 \mu \mathrm{M}$

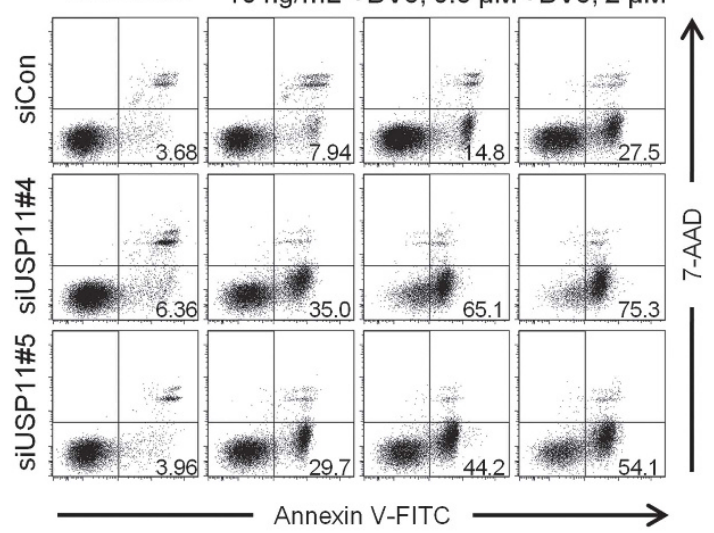

i

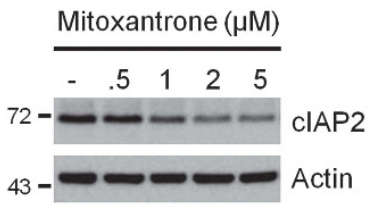

j

MG132 - - +

Mitoxantrone - + + WB: clAP1 $72-\longrightarrow$ WB: clAP2 $72-==$ WB: Actin d

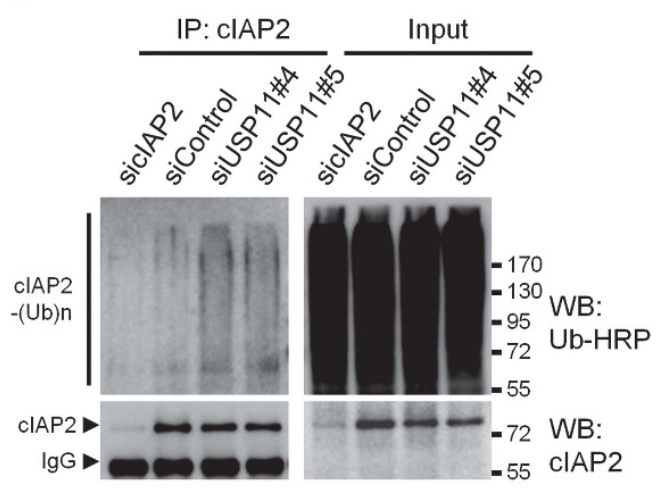

f $\lg \frac{\text { siCon }}{-1 \mathrm{~h} 2 \mathrm{~h}} \frac{\text { siUSP11 }}{-1 \mathrm{~h} 2 \mathrm{~h}}$ TNFa/BV6

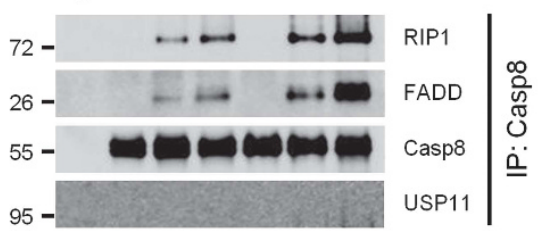
72 -

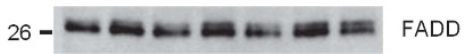

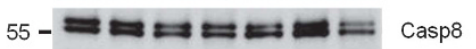
$95-$ - - n : $43-\longrightarrow-\infty-\infty-\infty+\infty$

h

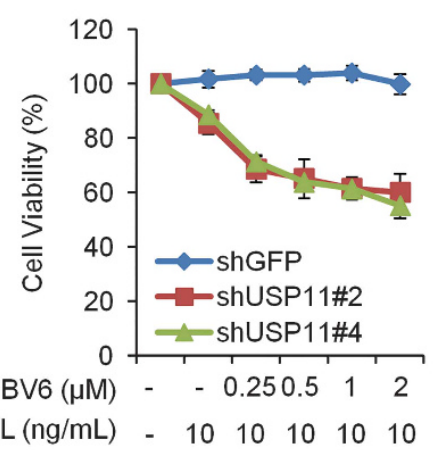

k \begin{tabular}{llllll}
0 & \multicolumn{2}{c}{ siCon } & & & \multicolumn{2}{c}{ siUSP11 } \\
\hline 0 & 8 & 16 & 0 & 8 & 16
\end{tabular} Mitoxantrone (h)

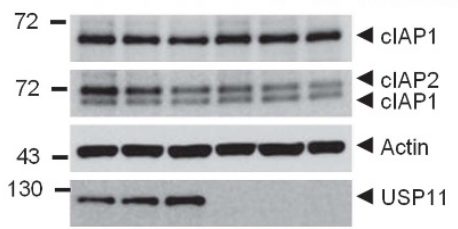


rescued clAP2 levels in USP11-depleted cells, which indicated that clAP2 is degraded through the proteasome upon USP11 depletion (Figure 4c). Furthermore, endo- genous ubiquitylated clAP2 accumulated in USP11depleted cells, suggesting that cIAP2 maintains its stability via USP11-dependent deubiquitylation (Figure 4d). Next, we a

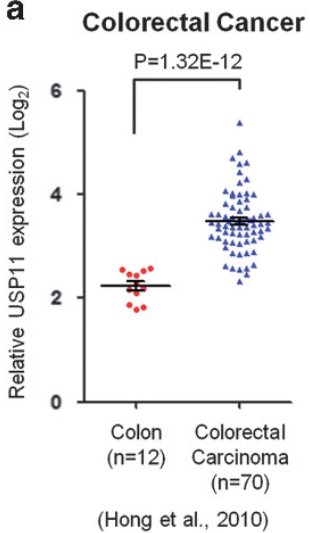

C

Colorectal Cancer

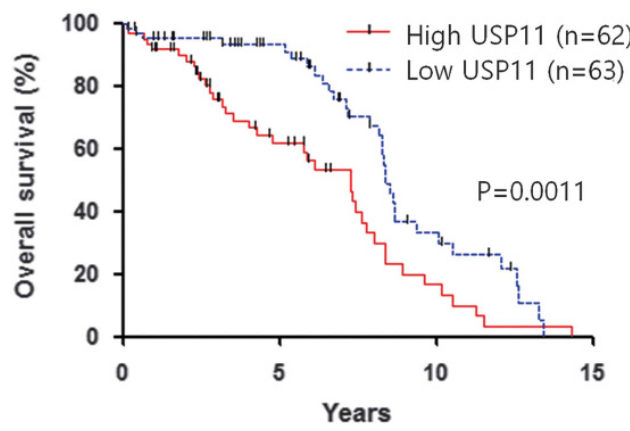

e

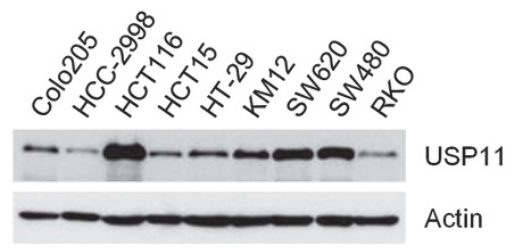

Colon cancer cell lines

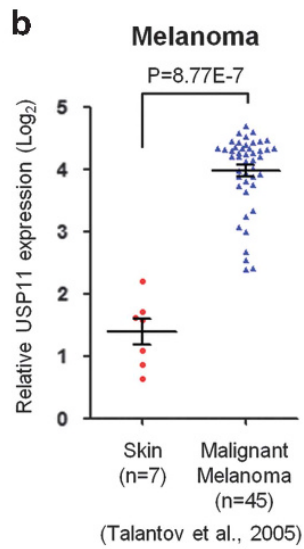

d

Melanoma

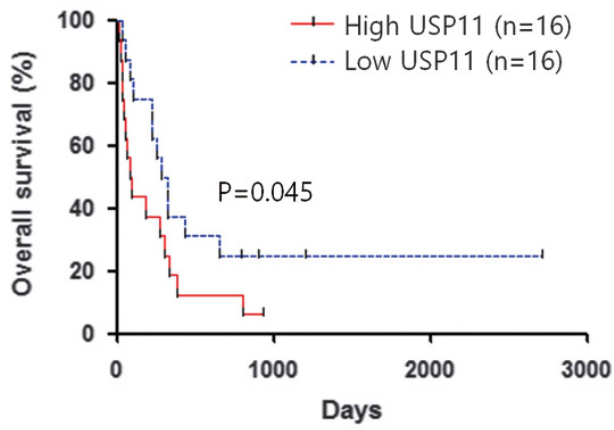

f

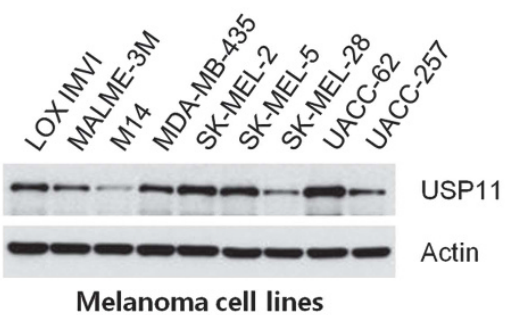

Figure 5 USP11 is overexpressed in colorectal cancer and melanoma and is associated with poor prognosis. (a and $\mathbf{b}$ ) USP11 expression in colorectal cancer and melanoma was evaluating using data sets (GSE9348, GSE3189). Please refer to the Materials and methods for details. (c) Kaplan-Meier survival curves of colon cancer patients with high or low levels of USP11, according to the median expression level, from data sets (GSE28814). Statistical significance was calculated using Log rank (Mantel-Cox) test. (d) Kaplan-Meier survival curves of melanoma patients with high (top 30\% of patients) or low (bottom of 30\% patients) levels of USP11 from data sets (GSE22153). Statistical significance was calculated using Gehan-Breslow-Wilcoxon test. (e and f) USP11 expression in colon cancer and melanoma cell lines was analyzed by WB

Figure 4 USP11 knockdown results in cIAP2 downregulation and sensitizes H1299 cells to BV6-induced apoptosis. (a and b) H1299 cells were transfected with two independent siRNAs against USP11. Major IAP members were detected by WB (a), and cIAP2 and USP11 mRNA levels were determined by qRT-PCR (b). (c) H1299 cells transfected with USP11 siRNAs were treated with $10 \mu \mathrm{M} \mathrm{MG132}$ for $12 \mathrm{~h}$, and protein levels were determined by WB. (d) H1299 cells transfected as indicated were treated with MG132 for $12 \mathrm{~h}$ and lysed in 1\% SDS. Cell lysates diluted in lysis buffer were immunoprecipitated with an anti-cIAP2 antibody. Ubiquitylated clAP2 was detected by WB using an HRP-conjugated anti-Ub antibody on a PVDF membrane denatured with Guanidine- $\mathrm{HCl}$. (e) USP11-knockdown $\mathrm{H} 1299$ cells were treated with the indicated concentration of BV6 for $30 \mathrm{~min}$ and analyzed by WB. (f) siRNA-transfected $\mathrm{H} 1299$ cells were treated with $20 \mathrm{ng} / \mathrm{ml} \mathrm{TNF} \alpha$ and $1 \mu \mathrm{M} \mathrm{BV6}$. Cell lysates were immunoprecipitated with anti-caspase-8, followed by WB, to detect RIP1 and FADD. (g) H1299 cells transfected with the indicated siRNAs were treated with TRAIL and BV6 for $4 \mathrm{~h}$. Cells were harvested, immediately stained with Annexin V and 7-AAD, and analyzed by flow cytometry. The Annexin V-positive/7-AAD negative fraction percentages are shown in dot plot data. (h) H1299 cells stably expressing USP11 shRNA were treated with TRAIL and BV6 for $6 \mathrm{~h}$. Cell viability was determined by measuring the levels of ATP. (i-k) H1299 cells were treated with increasing concentration of mitoxantrone for $16 \mathrm{~h}$ (i) or $2 \mu \mathrm{M}$ mitoxantrone in the presence of $10 \mu \mathrm{M}$ MG132 for $16 \mathrm{~h}$ (j). H1299 cells were transfected with USP11 siRNA and treated with $2 \mu \mathrm{M}$ mitoxantrone (k). clAP1/2 proteins were detected by WB using the indicated antibodies 
assessed whether USP11 downregulation could restore the sensitivity of ClAP2 to BV6, leading to cell death. Indeed, USP11-depleted cells exhibited rapid cIAP2 degradation by BV6, which was comparable to ClAP1 degradation (Figure 4e). In accordance with decreased clAP2 levels, complex II formation consisting of RIP1, FADD, and caspase- a

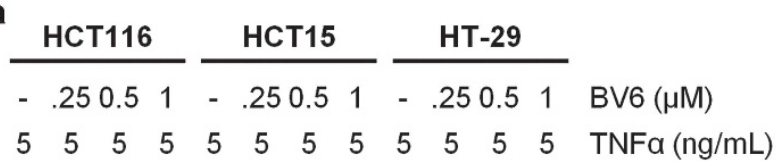

b

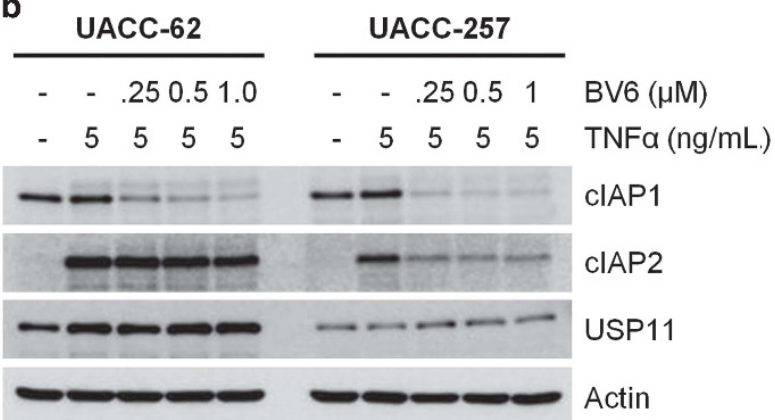

d

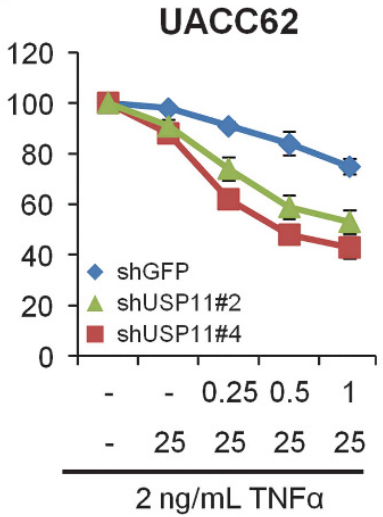

g

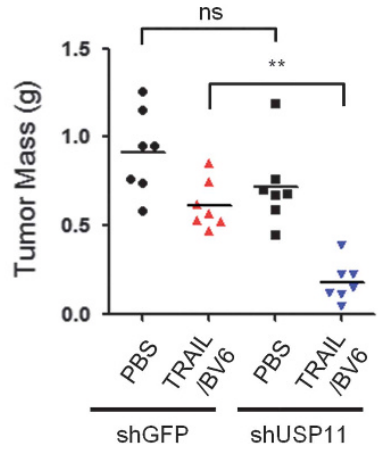

j

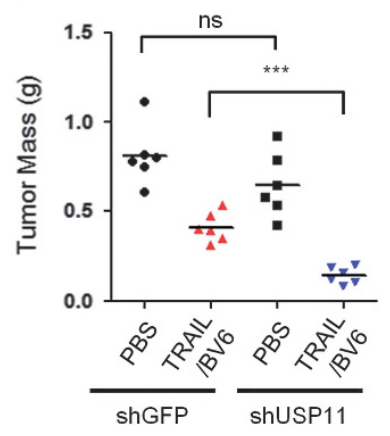

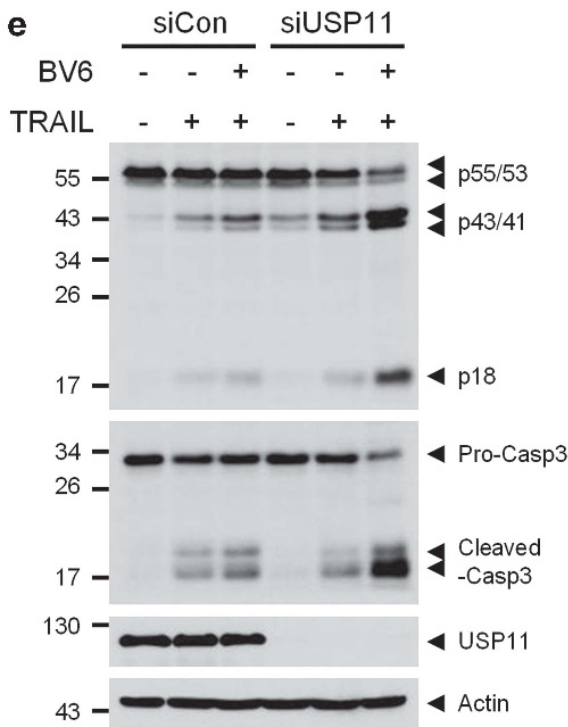

h

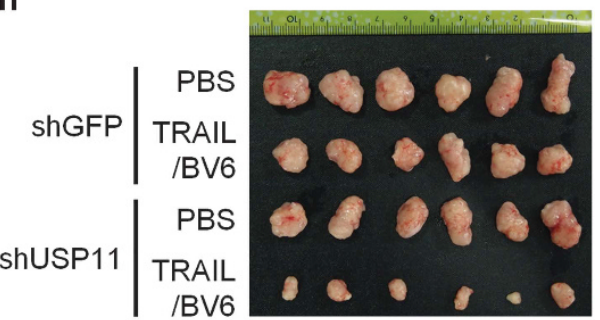

k

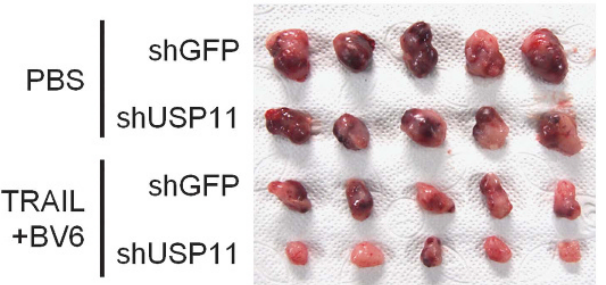


8 upon TNFa/BV6 treatment was increased, and caspase-8 was rapidly cleaved in USP11-depleted cells (Figure 4f; Supplementary Figure S3d). Finally, we found that USP11-depleted cells underwent rapid apoptosis following TRAIL/BV6 treatment (Figures $4 \mathrm{~g}$ and $\mathrm{h}$ ). Recently, mitoxantrone was identified as a USP11 inhibitor. ${ }^{34}$ Consistently, USP11 inhibition by mitoxantrone induced clAP2 destabilization, which was reversed with MG132 treatment (Figures 4h-i). USP11 depletion by siRNA abrogated mitoxantrone-induced clAP2 degradation, suggesting that mitoxantrone regulates clAP2 degradation via USP11 inhibition (Figure 4j). Furthermore, mitoxantrone sensitized cells to BV6- or birinapant-induced cell death (Supplementary Figure S3e). Taken together, our data indicate that USP11 is a positive clAP2 regulator that prevents apoptotic cell death.

Previous reports have suggested that USP11 regulates $\mathrm{TNF} a$-induced NF- $\kappa \mathrm{B}$ activation through direct interaction with IKK or $I_{K B a}{ }^{35,36}$ Because the NF- $k$ B-dependent survival pathway is crucial for suppression of TNFa-dependent apoptosis, we monitored NF- $\mathrm{BB}$ activation and JNK activation in USP11-depleted cells. Consistent with previous reports, we found that USP11 depletion slightly enhanced $I_{\kappa} \mathrm{B} a$ phosphorylation and NF- $\kappa$ B target gene expression, such as TNF $a$ and $\mathrm{IL}-8$, in response to TNFa (Supplementary Figure S4a). ${ }^{35,36}$ JNK activation and clAP2 expression were similar in control and USP11-depleted cells (Supplementary Figure S4b). Despite the slight increase in NF- $k \mathrm{~B}$ activity, which contributes cell survival, USP11 depletion eventually led to cell death via clAP2 downregulation upon TNFa stimulation. Overall, depletion of USP11 in cells accelerated complex II formation and apoptotic cell death by destabilizing clAP2.

USP11 is overexpressed in colon cancer and melanoma. We next investigated the function of USP11 in a more physiological context. Through mining of the Oncomine database, we found that USP11 is overexpressed in several cancers, including colorectal cancer and melanoma (Figures $5 \mathrm{a}$ and b). USP11 overexpression in colorectal cancer was also evident in another public data set (Supplementary Figure S5a). Furthermore, increased USP11 expression was detected in human melanoma metastases or colorectal cancers with relapse (Supplementary Figures S5b and c). Notably, we found that patients from various data sets with high USP11 levels exhibited poor prognosis (Figures $5 c$ and d). On the basis of these data, we analyzed USP11 expression levels in several colon cancer and melanoma cell lines and found that the USP11 expression levels varied between cell lines (Figures $5 \mathrm{e}$ and f). For colon cancer cell lines, HCT116 cells showed high USP11 levels, whereas HCT-15 and HT-29 cells expressed USP11 at low levels (Figure 5e). We first tested these cells for clAP2 status upon TNF $a$ and BV6 treatment; when HCT-15 and HT-29 cells were pretreated with a low concentration of TNFa followed by BV6, clAP1 and clAP2 were rapidly degraded, whereas clAP2 degradation was hindered in HCT116 cells (Figure 6a). These data suggest that USP11 overexpression may protect cancer cells against BV6 treatment. Supporting this hypothesis, USP11 depletion in HCT116 cells, but not in HCT-15 and HT-29 cells, sensitized cells to TNFa- and BV6-induced death processes (Supplementary Figure S6a). In the melanoma cell lines UACC-62 and UACC-257, clAP2 was barely detectable but considerably increased following TNFa stimulation. Among these two cell lines, UACC-62 melanoma cells with high USP11 levels were protected against BV6-induced cIAP2 degradation and cell death compared with UACC-257 cells expressing low USP11 levels (Figure 6b; Supplementary Figure S6b). Because TNFa-induced clAP2 expression potentially inhibits TRAIL-mediated apoptosis, we next investigated the roles of USP11 in TRAIL/BV6-mediated apoptosis in the presence of TNFa. USP11 knockdown significantly accelerated TRAIL/BV6-induced cell death in HCT116 cells, but not in HCT15 and HT-29 cells (Figure 6c; Supplementary Figure S6c). Consistently, USP11 depletion successfully restored BV6 sensitivity to TRAIL/BV6-induced apoptotic cell death in TNFa-pretreated UACC-62 cells (Figure 6d). Similar to BV6, birinapant showed limited clAP2 degradation in HCT116 and UACC-62 cells, which express high USP11 levels (Supplementary Figures S7a and b). Upon USP11 depletion, cell death mediated by TNFa and birinapant was accelerated as expected (Supplementary Figures S7c and d).

To verify the in vivo roles of USP11 in TRAIL/Smac mimeticmediated tumor suppression, we used a xenograft tumor model consisting of HCT116 cells and UACC-62 cells expressing shGFP or shUSP11. These cells were injected into nude mice followed by BV6 and TRAIL treatment, and we found that the growth of HCT116/shUSP11 cell xenografted tumors was significantly slower upon treatment with TRAIL/ BV6 compared with HCT116/shGFP cells (Figure 6f). The final mean tumor size and mass of control xenograft tumors treated with TRAIL/BV6 (631.5 $\mathrm{mm}^{3}$ and $0.62 \mathrm{~g}$, respectively) were greatly decreased in USP11-depleted xenograft tumors (288.3 $\mathrm{mm}^{3}$ and $0.18 \mathrm{~g}$, respectively) (Figures $6 \mathrm{f}-\mathrm{h}$ ). Similarly, UACC-62 melanoma xenografts also indicated that USP11 downregulation enhanced TRAIL/BV6 antitumor activity (700.6-289.3 mm $\left.\mathrm{mm}^{3}, \quad 0.41-0.14 \mathrm{~g}\right)$ (Figures 6i-k). Taken together, these data imply that USP11 downregulation in colon cancer and melanoma effectively improves the tumor suppressive activity of TRAIL and BV6 in vivo.

Figure 6 USP11 downregulation restores cell sensitivity to BV6 and enhances TRAIL and BV6 antitumor activity. (a and b) Colon cancer cell lines (a) and melanoma cell lines (b) were pretreated with $5 \mathrm{ng} / \mathrm{ml}$ TNF $\alpha$ for $12 \mathrm{~h}$, followed by BV6 treatment for 30 min. clAP protein levels were determined by WB. (c, d) HCT116 cells stably expressing shUSP11 (c) or UACC-62 cell lines transfected with siRNA (d) were treated with $2 \mathrm{ng} / \mathrm{ml} \mathrm{TNF} \alpha$ for $12 \mathrm{~h}$, followed by TRAIL and BV6 stimulation for $8 \mathrm{~h}$ as indicated. Cell viability was determined by measuring the levels of ATP. (e) USP11-knockdown UACC-62 cells were pretreated with TNF $\alpha$ followed by TRAIL and BV6 treatment for 6 h. Caspase-8 and -3 cleavage was determined by WB. (f-h) HCT116 cells expressing shGFP or shUSP11 were injected into the flanks of nude mice. One week after inoculation, mice were treated with TRAIL $(5 \mathrm{mg} / \mathrm{kg})$ and BV6 (10 mg/kg) by i.p. injection as indicated. Tumor growth is shown in the graph (f), and tumors are shown in (g). Tumor mass is summarized in (h). Data represent the mean \pm S.D.; two-tailed Mann-Whitney test, $n s=$ non-significant, ${ }^{*} P<0.01(n=7)$. (i-k) UACC-62 cells expressing shGFP or shUSP11 were injected into the flanks of nude mice. One week after inoculation, mice were treated with TRAlL $(5 \mathrm{mg} / \mathrm{kg})$ and BV6 $(10 \mathrm{mg} / \mathrm{kg})$ by i.p. injection. Tumor growth is shown in the graph (i), and tumors are shown in (j). Tumor mass is summarized in (k). Data represent the mean \pm S.D.; two-tailed Mann-Whitney test, ns $=$ non-significant, ${ }^{* *} P<0.01,{ }^{* \star *} P<0.001(n=6)$ 
TNFa stimulation stabilizes USP11 via the JNK pathway. We next evaluated whether USP11 contributes to cIAP2 accumulation upon TNFa treatment. The results showed that USP11 protein accumulated, with a 2.26 -fold increase in mRNA levels, upon TNFa stimulation (Figures $7 a$ and b). There was no obvious change in USP11 protein turnover rate in the presence or absence of TNFa, suggesting that USP11 expression is rather regulated at the transcriptional level (Supplementary Figure S8). While USP11-depleted cells exhibited similar clAP2 mRNA levels, they failed to increase clAP2 protein levels, suggesting that USP11 is responsible for clAP2 maintenance after TNFa stimulation a
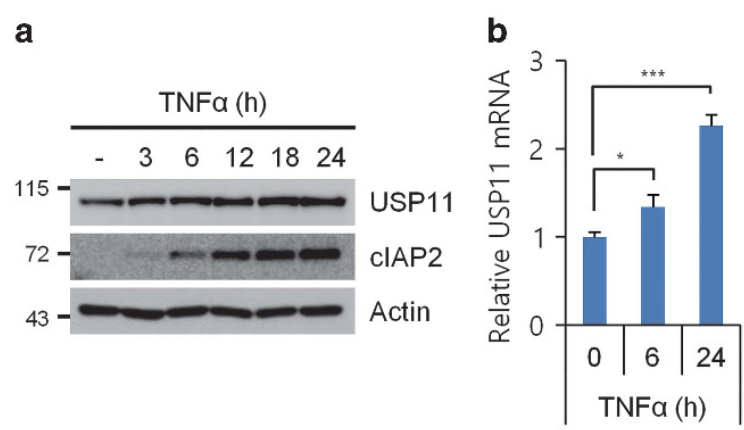

d
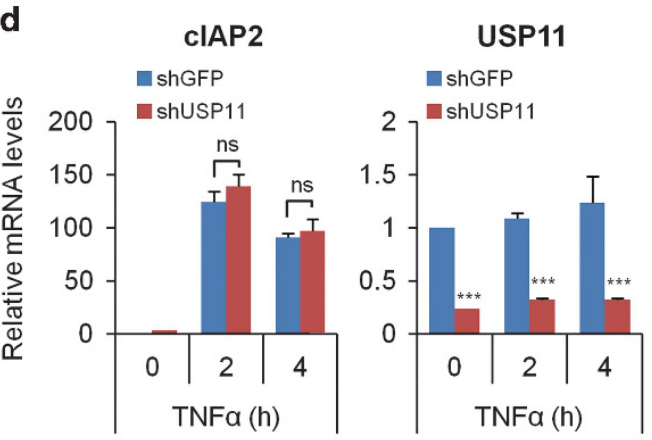

f
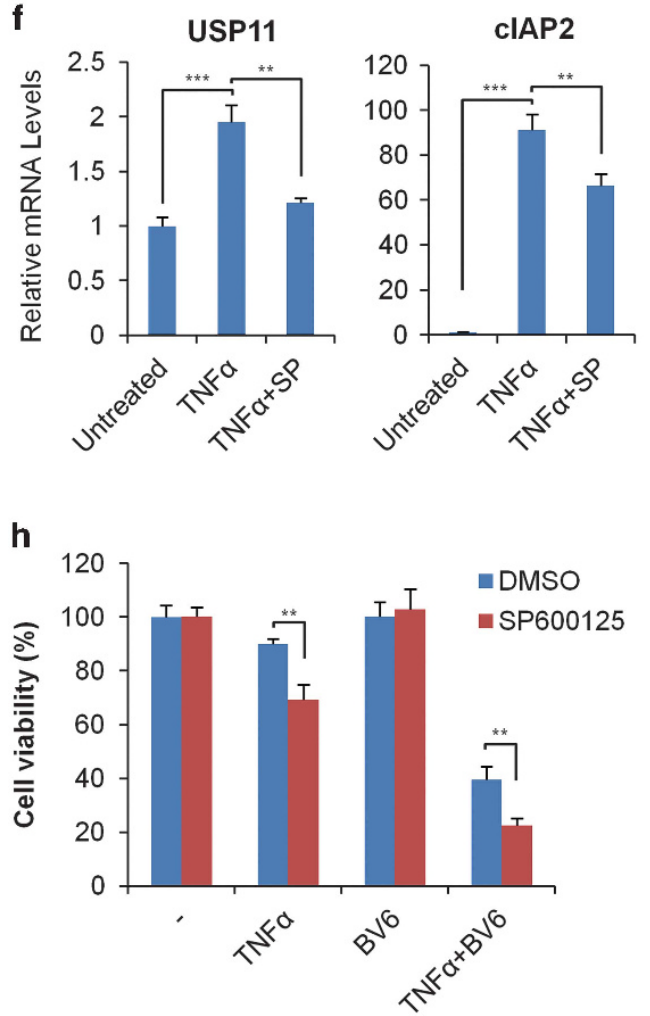

g

i c

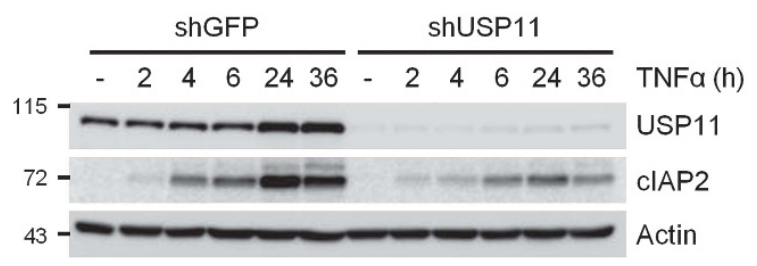

e

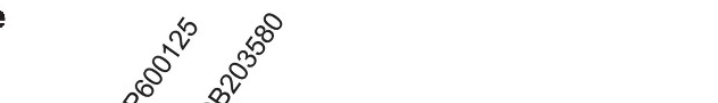

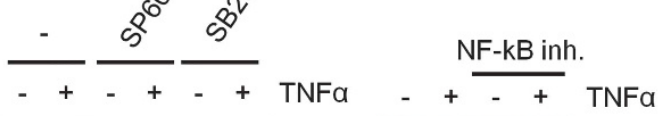
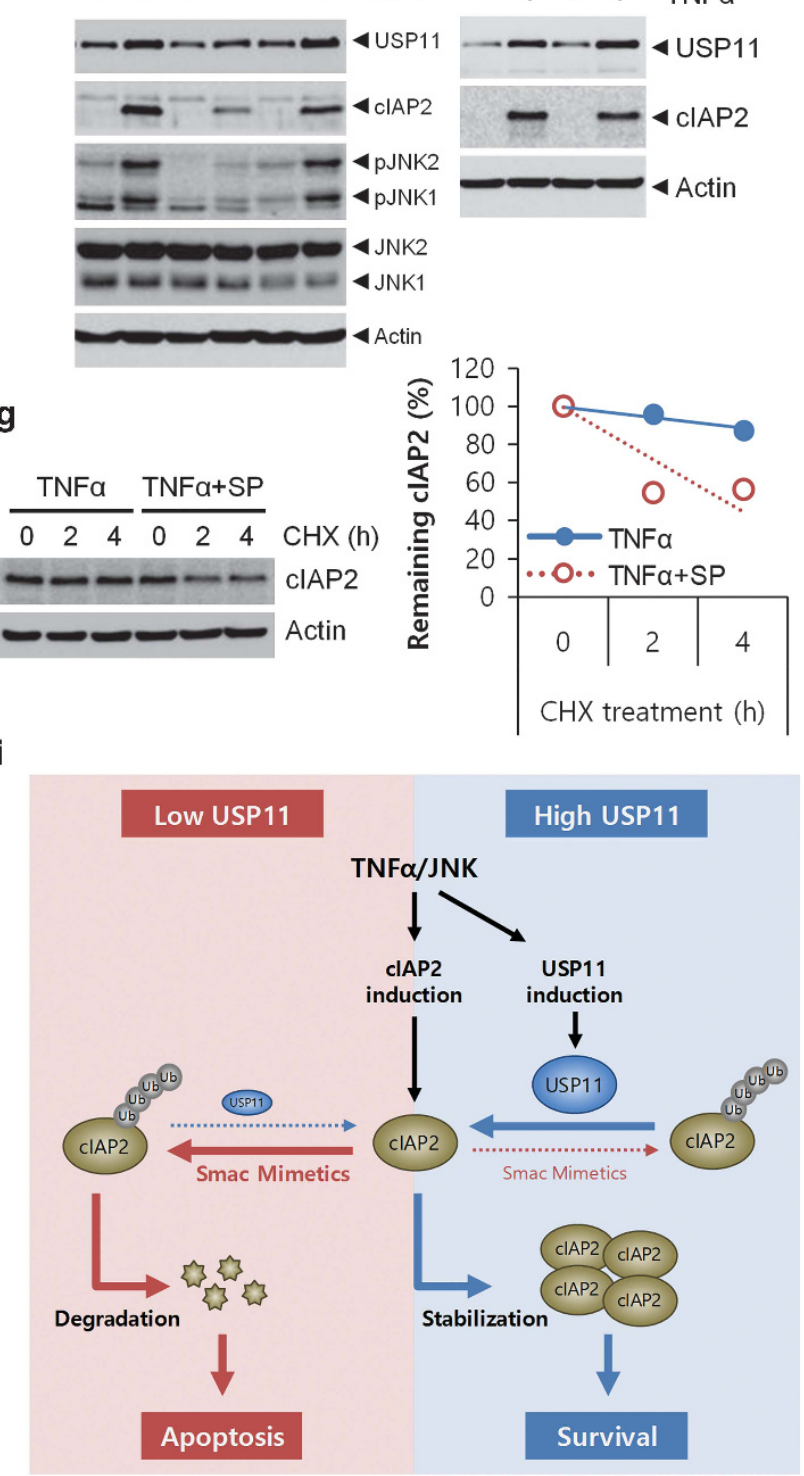
(Figures 7c and d). Next, we investigated the downstream pathway responsible for USP11 induction by treating cells with NF-kB, JNK, and p38 inhibitors. Among the three major pathways activated by TNFa signaling, we found that only JNK signaling suppressed USP11 transcription (Figures 7e and f). Consistent with previous reports, we found that JNK inhibition also reduced the protein and mRNA levels of clAP2 (Figures 7e and f). ${ }^{37}$ Interestingly, the JNK inhibitor SP600125 also decreased the half-life of clAP2 protein, suggesting that JNK positively regulates clAP2 expression by increasing transcription and USP11-mediated protein stability (Figure 7g). Consistent with the JNK-mediated changes in USP11 and clAP2 expression levels, JNK inhibition accelerated TNFa or TNFa/BV6-induced apoptosis (Figure 7h). Thus, our data suggest that TNFa primarily prevents apoptosis by activating JNK-USP11-clAP2, in addition to the NF-KB pathway; in contrast, JNK or USP11 inhibition downregulates clAP2 expression and sensitizes cells to TNFa-induced apoptosis.

\section{Discussion}

Cancer cells express several IAPs, including cIAP1/2, XIAP, and Survivin, to evade apoptosis induced by various stimuli. ${ }^{4,5,38}$ Among these, clAP1 and 2 are highly homologous and have been considered functionally redundant. ${ }^{4}$ Most biological studies have focused on clAP1 rather than clAP2 because clAP1 is more highly expressed under normal conditions, suggesting its predominant role. ${ }^{39}$ In contrast, the absence of both clAP1 and clAP2 is required for complete inhibition of TNFa-mediated survival, suggesting that these inhibitors have redundant functions. ${ }^{20,21}$ Evidence also supports that clAP2 has independent roles from clAP1 in suppressing apoptosis. For examples, we and others have found that the levels of clAP2, but not clAP1, are greatly increased after TNFa stimulation. clAP2 is also induced by $\mathrm{IL}-1 \beta$ and cisplatin, leading to apoptosis resistance. ${ }^{40,41}$ In addition to these observations, elevated clAP2 expression in certain cell lines renders cells resistant to Smac mimetics, suggesting that clAP2 is the decisive factor for protecting cancer cells from Smac mimetic-induced apoptosis. ${ }^{22}$

In this study, we show that a USP11-dependent mechanism selectively and specifically regulates cIAP2 stability independent of clAP1, which may explain the diverse responses of cancer cells to treatment with Smac mimetics, which are currently being tested in the clinic (Figure 7i). ${ }^{5,14}$ In contrast to clAP1, the clAP2 degradation rate upon Smac mimetic treatment largely varied between cell lines and correlated with USP11 expression. For example, clAP2 expression in cells with high USP11 levels such as H1299, HCT116, and
UACC-62 was associated with strong resistance against Smac mimetic treatment. When USP11 was depleted in these cell lines, BV6 or birinapant induced clAP2 degradation markedly increased, with a notable increase in TNFa or TRAIL-induced apoptosis. The results reported here suggest that USP11-induced clAP2 stabilization may be a decisive factor for determining cellular fate upon treatment with Smac mimetics.

Given their critical roles in apoptosis inhibition, IAPs are attractive therapeutic targets. While the Smac mimetics can induce apoptosis through autocrine TNFa, cancer cells often overcome Smac mimetic-induced antitumor activities. Therefore, other strategies to stimulate cell death pathways have been studied to overcome Smac mimetic resistance. Because IAPs primarily control the extrinsic apoptosis pathway, combination treatment with TRAIL synergistically enhanced their antitumor activity in xenograft experiments in various cancer models. ${ }^{16,42}$ In addition, concomitant inhibition of receptor tyrosine kinases (RTKs), which are often activated by Smac mimetics, successfully enhanced the antitumor effects in a xenograft model. ${ }^{29,43}$ Recently, combination treatment with a demethylating agent largely improved the tumor-suppressive effects of Smac mimetics in several cancer models. ${ }^{27,44}$ In addition to these, numerous new compounds including LCL161 and birinapant are currently in phase I and II clinical trials. ${ }^{5,14}$ As our data suggest, clAP2 sensitivity against Smac mimetics in relation to USP11 expression should be considered in the abovementioned combination therapies. Using specific shRNAs, we showed that USP11 downregulation in colon cancer and melanoma efficiently suppressed tumor growth in xenograft models. In addition, the type II topoisomerase inhibitor mitoxantrone, which is widely used for the treatment of various tumor types, was recently identified as an USP11 inhibitor. Although mitoxantrone involves various pathways, such as inhibition of topoisomerase and induction of immunogenic cell death, to suppress tumor growth, ${ }^{45-47}$ our data suggest that inhibition of the USP11-cIAP2 pathway by mitoxantrone contributes to its anticancer effects. Thus, combination treatment with mitoxantrone and Smac mimetics and/or TRAIL may synergistically enhance the desired antitumor effects.

Finally, we found that USP11 expression was increased in response to TNFa, implying the relevance of USP11 function in TNFa signaling (Figure 7i). TNFa triggers a variety of downstream signaling pathways such as NF- $K B$, JNK, and p38. In particular, NF- $k$ B activation following TNFa stimulation induces the expression of several pro-inflammatory and prosurvival genes. TNFa-mediated JNK signaling activates a wide array of genes via the AP-1 transcription factor. Although

Figure 7 USP11 is induced via the JNK pathway and stabilizes clAP2 protein upon TNF $\alpha$ stimulation. (a) UACC-62 cells were treated with $10 \mathrm{ng} / \mathrm{ml}$ TNF $\alpha$ for the indicated time period, and USP11 and cIAP2 expression was determined by WB. (b) CIAP2 and USP11 transcript levels in TNF $\alpha$-treated UACC-62 cells were measured by qRT-PCR. (c and d) UACC62 cells expressing shUSP11 were treated with TNF $\alpha$ as indicated. USP11 and cIAP2 protein and mRNA levels were analyzed by WB (c) and qRTPCR (d), respectively. (e) UACC-62 cells were pretreated with a JNK inhibitor (SP600125, $20 \mu \mathrm{M})$, p38 MAPK inhibitor (SB203580, $20 \mu \mathrm{M})$, or the NF-kB inhibitor IV $(10 \mu \mathrm{M})$ 30 min before TNF $\alpha$ treatment. Twenty-four hours after TNF $\alpha$ treatment, cell lysates were analyzed by WB. (f) UACC-62 cells were treated with TNF $\alpha$ in the presence of SP600125. mRNA levels were determined by qRT-PCR. (g) UACC-62 cells were pretreated with TNF $\alpha$ in the absence or presence of SP600125 for $12 \mathrm{~h}$. Cells were treated with $50 \mu \mathrm{g} / \mathrm{ml} \mathrm{CHX}$ for the indicated time period, and clAP2 stability was determined by WB. Relative amounts of clAP2 were calculated after normalizing to actin, and are shown in the right panel. (h) UACC-62 cells were treated with a combination of TNF $\alpha$, BV6, and SP600125 for $24 \mathrm{~h}$. Cell viability was determined by measuring the levels of ATP. (i) Schematic model of USP11-mediated cIAP2 regulation following TNF $\alpha$ stimulation. (Data represent the mean $\pm S . D$.; $n=3,{ }^{*} P<0.05,{ }^{* *} P<0.01$, $\left.{ }^{* * *} P<0.001\right)$ 
clAP2 has been identified as an NF- $\kappa$ B target, it is also upregulated by the JNK-AP-1 pathway. ${ }^{37}$ Supporting these data, we found that clAP2 induction upon TNFa stimulation was suppressed following treatment with a JNK inhibitor. Interestingly, this JNK inhibitor caused a decrease in USP11 mRNA and protein levels, suggesting that the JNK pathway is responsible for cIAP2 and USP11 induction. In addition, TNFa/ JNK-dependent USP11 induction may serve as a major clAP2-stabilizing factor, as clAP2 accumulation following TNFa stimulation was suppressed in USP11-depleted cells. Because JNK is involved in various signaling pathways, its roles in apoptosis remain controversial and likely depend on different cellular contexts. JNK activation primarily leads to apoptosis by increasing pro-apoptotic gene transcription or by directly activating mitochondrial apoptosis. ${ }^{48,49}$ However, JNK inhibition by SP600125 can also sensitize cells to death in certain conditions, suggesting that JNK may have antiapoptotic functions. ${ }^{50,51}$ Consistently, our data have shown that JNK inhibition downregulated both USP11 and CIAP2, thereby accelerating TNF $\alpha$ - or TNFa/BV6-induced cell death. Our results further suggest that JNK may represent a clinical target along with TRAIL and Smac mimetics. To summarize, our studies identified a novel survival axis involving TNFa/JNK/USP11/clAP2, which may function to protect cells from extrinsic apoptotic stimuli. On the basis of these observations, USP11 and clAP2 should be considered therapeutic markers and targets. Targeting these molecules may serve as an effective tumor treatment in combination with TRAIL and Smac mimetics.

\begin{abstract}
Materials and methods
Plasmids. Sixty-seven FLAG-HA-DUB constructs were purchased from Addgene (http://www.addgene.org). ${ }^{52}$ The pCMV-FLAG-USP11 vector was kindly provided by JH Chung (Seoul National University, Seoul, Korea) and was subcloned into pGEX-4T-1. Myc-clAP2 constructs were kindly provided by SY Lee (Ewha Woman's University Ewha, Seoul, Korea), and pcDNA3-His-Ub was kindly provided by DP Lane. ${ }^{53}$ pHM6-HA-Ub has been described previously. ${ }^{54}$ The pEGFP-C2 (Clontech, San Diego, CA, USA) and pCS3-MT-6XMyc vectors were
\end{abstract} used as transfection controls.

Antibodies and chemicals. The following antibodies were used: CIAP2 (3130; Cell Signaling, Danvers, MA, USA, AF8171; R\&D Systems, Minneapolis, MN, USA), CIAP1 (AF8181; R\&D Systems), XIAP (2045; Cell Signaling), ML-IAP (5471; Cell Signaling), Survivin (2808; Cell Signaling), USP11 (sc-365528; Santa Cruz, Santa Cruz, CA, USA), Caspase-8 (9746; Cell Signaling, sc-6136; Santa Cruz), Caspase-3 (9662; Cell Signaling), hFADD (610399; BD Transduction Laboratories, Franklin lakes, NJ, USA), RIP1 (610409; BD Transduction Laboratories), $\quad \kappa_{\kappa} \mathrm{B} \alpha$ (4814; Cell Signaling), Phospho- $\mid \kappa \mathrm{B} \alpha$ (Ser32) (2859; Cell Signaling), NF- $\kappa B$ p65 (sc-8008; Santa Cruz), Phospho-NF- $\kappa$ B p65 (Ser536) (3033; Cell Signaling), SAPK/JNK (9258; Cell Signaling), Phospho-SAPK/JNK (Thr183/Tyr185) (9251; Cell Signaling), HRP-conjugated- $\alpha$-Ub FK2 (PW0150; Biomol-Enzo, Farmingdale, NY, USA), HA (sc-805 rabbit; Santa Cruz, 3F10 rat; Roche, Mannheim, Germany, 12013819001), FLAG (F3165 mouse, F7425 rabbit; Sigma-Aldrich, St. Louis, MO, USA), GST (sc-138; Santa Cruz), GFP (sc-8334; Santa Cruz), Myc (sc-40; Santa Cruz), $\beta$-actin (A5316; Sigma), normal mouse IgG (sc-2025; Santa Cruz), normal rabbit lgG (sc-2027; Santa Cruz), and normal goat IgG (sc2028; Santa Cruz). BV6 was kindly provided by D Vucic (Genentech, San Francisco, CA, USA). PQE-His-TRAIL was a kind gift from SH Kim (Korea National Cancer Center, Seoul, Korea) and was used for the purification of His-tagged human TRAIL and for in vivo experiments as previously reported. ${ }^{55}$ CHX (C4859), N-ethylmaleimide (NEM, E3876), human recombinant TNF $\alpha$ (T0157), ActD (A4262), and dimethyl sulfoxide (DMSO) were purchased from Sigma-Aldrich. MG132 was purchased from A.G. Scientific (San Diego, CA, USA). Mitoxantrone (S1889), SP600125 (JNK inhibitor, S1460), and SB203580 (p38 MAPK inhibitor, S1076) were purchased from Selleck Chemicals (Huston, TX, USA). NF- $\kappa$ B Activation Inhibitor IV (481412) was purchased from Merck (Darmstadt, Germany).

Cell culture, transfection, and cell viability analysis. H1299 (human lung carcinoma cell line), HeLa (cervical cancer cell line), 293FT (human embryonic kidney), and MDA-MB-231 (breast cancer cell line) cells were maintained in Dulbecco's modified Eagle's medium (DMEM, Corning Cellgro, Manassas, VA, USA) supplemented with $10 \%$ fetal bovine serum (Corning Cellgro) and $1 \%$ penicillin/streptomycin (Invitrogen, Carlsbad, CA, USA) in $5 \% \mathrm{CO}_{2}$ at $37^{\circ} \mathrm{C}$. Colo205, HCC-2998, HCT116, HCT15, HT-29, KM12, SW620, SW480, and RKO cells (human colon cancer cell lines) and LOX-IMVI, MALME-3M, M14, MDAMB-435, SK-MEL-2, SK-MEL-5, SK-MEL-28, UACC-62, and UACC-257 cells (melanoma cell lines) were maintained in RPMI with 10\% FBS and antibiotics (GIBCO, Grand Island, NY, USA). PEI (Sigma-Aldrich) was used to transfect 293FT cells, and Lipofectamine 2000 was used to transfect 293FT cells for lentivirus production. To determine cell viability, cells were incubated with Cell Titer Glo reagent and analyzed with a luminometer according to the manufacturer's protocol (Cell Titer Glo Luminescent Cell Viability Assay kit, G7571, Promega, Madison, WI, USA).

Immunoprecipitation and DISC immunoprecipitation. Cells were lysed in a buffer composed of $50 \mathrm{mM}$ Tris- $\mathrm{HCl}(\mathrm{pH} 7.5), 150 \mathrm{mM} \mathrm{NaCl}, 0.5 \%$ Triton $\mathrm{X}-100$, and $1 \mathrm{mM}$ EDTA containing a protease inhibitor cocktail. The cell lysates were immunoprecipitated by incubation with antibodies for $2 \mathrm{~h}$, followed by incubation with protein G sepharose (GE Healthcare, Buckinghamshire, UK) for $2 \mathrm{~h}$. Then, the immunoprecipitates were boiled in $2 \mathrm{X}$ sample buffer for $5 \mathrm{~min}$. For DISC immunoprecipitation, cells were treated with TNF $\alpha(20 \mathrm{ng} / \mathrm{ml})$ and BV6 $(1 \mu \mathrm{M})$ in the presence of zVAD-fmk $(20 \mu \mathrm{M})$ for 1 or $2 \mathrm{~h}$. Cells were lysed in DISC immunoprecipitation buffer containing $50 \mathrm{mM}$ Tris- $\mathrm{HCl}(\mathrm{pH} 7.5), 150 \mathrm{mM} \mathrm{NaCl}$, $1 \%$ Triton X-100, 10\% glycerol, and $1 \mathrm{mM}$ EDTA with a proteasome inhibitor cocktail. DISC complexes were purified by immunoprecipitation using an $\alpha$-Caspase-8 goat (sc-6136) antibody, followed by WB analysis using $\alpha$-FADD mouse (610399), $\alpha$-Caspase-8 mouse (\#9746), and $\alpha$-RIP1 mouse (610409) antibodies.

Protein purification and in vitro binding assays. Recombinant human USP11 protein was expressed in Escherichia coli using the pGEX-4T-1 plasmid and purified using glutathione sepharose $4 B$ (GE Healthcare). Recombinant human CIAP1 (818-IA) and CIAP2 (817-P2) were purchased from R\&D Systems. Recombinant CIAP1 or cIAP2 was incubated with GST or GST-USP11 for $2 \mathrm{~h}$, and then glutathione sepharose was added to the mixture and incubated for $1 \mathrm{~h}$. GST complexes were washed and eluted in $10 \mathrm{mM}$ reduced glutathione. Proteins were analyzed by WB.

In vivo and in vitro deubiquitylation assays. The ubiquitylation assay was performed as described previously. ${ }^{56}$ Briefly, cells were lysed in $6 \mathrm{M}$ guanidine- $\mathrm{HCl}$ buffer $(\mathrm{pH}$ 8) containing $5 \mathrm{mM}$ NEM (Sigma-Aldrich), and His-ubiquitin-conjugated proteins were purified by $\mathrm{Ni}^{2+}$-NTA (Qiagen, Valencia, CA, USA) and analyzed by western blotting (WB). For ubiquitylation assays using $\mathrm{HA}-\mathrm{Ub}$, cells were lysed under denaturing conditions containing $1 \%$ SDS. Cell lysates were immunoprecipitated, followed by WB with a horseradish peroxidase (HRP)-conjugated anti-HA antibody (12013819001, Roche). For the detection of

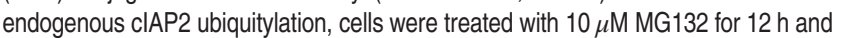
harvested in PBS containing NEM and lysed in 1\% SDS. Cell lysates were immunoprecipitated with anti-clAP2 antibodies (3130, Cell Signaling) in lysis buffer containing $0.1 \%$ SDS, followed by WB. Transferred proteins were denatured using $6 \mathrm{M}$ guanidine- $\mathrm{HCl}$, followed by WB using an HRP-conjugated anti-Ub antibody (FK2, PW0150, Biomol-Enzo). For in vitro ubiquitylation, ubiquitylated Myc-cIAP2 was obtained from 293FT cells transiently expressing Myc-cIAP2 and HA-Ub by immunoprecipitating cIAP2 using anti-Myc antibody as described above. FLAGUSP11 was purified from 293FT cells expressing FLAG-USP11 using ANTI-FLAG M2 Affinity Gel (A2220, Sigma) and eluted with FLAG peptide (F3290, Sigma) according to the manufacturer's protocol. Ubiquitylated CIAP2 was incubated with purified FLAG-USP11 in deubiquitylation buffer containing $40 \mathrm{mM}$ Tris- $\mathrm{HCl}(\mathrm{pH} 7.6)$, $50 \mathrm{mM} \mathrm{NaCl}, 5 \mathrm{mM} \mathrm{MgCl} 2,5 \mathrm{mM}$ DTT, and $2 \mathrm{mM}$ ATP for $6 \mathrm{~h}$. The ubiquitylation status of CIAP2 was detected by WB using HRP-conjugated anti-HA antibody or anti-clAP2 antibody. 
USP11 knockdown using siRNA and shRNA. Two USP11 flexitube siRNAs (siUSP11\#4, (AC)CGATTCTATTGGCCTAGTA and siUSP11\#5, (CT)GCGT CGGGTACGTGATGAA) were purchased from Qiagen and resynthesized. Control siRNA (siCon, 1027281) was also purchased from Qiagen. The ON-TARGET plus SMARTpool for human CIAP1 siRNA (L-004390-00), human ClAP2 siRNA (L-004099-00), and a non-targeting pool (siNON, D-001810-10) were purchased from Dharmacon/Thermo Scientific (Waltham, MA, USA). Cells were transfected with siRNAs using Lipofectamine and RNAiMax (Invitrogen) via the reverse-transfection method according to the manufacturer's protocol. Mission lentiviral shRNA expression vectors for human USP11 (shUSP11\#2, TRCN0000007359, CCGGCCGTGATGATATCTTCGTCTACTCGAGTAGACGAAGA TATCATCACGGTTTTTG, and shUSP11\#4, TRCN0000315154, CCGGCCGTGA CTACAACAACTCCTACTCGAGTAGGAGTTGTTGTAGTCACGGTTT TTG) and control GFP were purchased from Sigma-Aldrich. 293FT cells were transfected with pLKO.1 shRNA-expressing vector and packaging vectors for $48 \mathrm{~h}$, and supernatants were harvested, filtrated, and transferred to H1299, HCT116, and UACC-62 cells. shRNA-expressing cells were selected following $1-2 \mu \mathrm{g} / \mathrm{ml}$ puromycin treatment for 7 days.

qRT-PCR analysis. Total RNA was extracted with Trizol reagent (Invitrogen) according to the manufacturer's instructions. CDNA was synthesized from $1 \mu \mathrm{g}$ total RNA using PrimeScript Reverse Transcriptase (2680A; Takara Bio, Shiga, Japan), amplified, and analyzed with the QuantiTect SYBR Green PCR Kit followed by qRT-PCR (Qiagen) with the following primers:

USP11, 5'-CAAGAACAAGGTTGGCCATT-3' (forward) and 5'-TCGCACAGCTCC ACATACTC-3' (reverse)

CIAP2, 5'-ATTTGATGAAAAGCGCCAAC-3' (forward) and 5'-AAACCAGCACGA GCAAGACT-3' (reverse)

TNF $\alpha, 5^{\prime}$-AACCTCCTCTCTGCCATCAA-3' (forward) and 5'-GGAAGACCCCTC CCAGATAG-3' (reverse)

IL-8, 5'-GTGCAGTTTTGCCAAGGAGT-3' (forward) and 5'-AAATTTGGGGTG GAA AGG TT-3' (reverse)

GAPDH, 5'-GATCATCAGCAATGCCTCCT-3' (forward) and 5'-TGTGGTCATGA GTCCTTCCA-3'(reverse)

Analysis of USP11 expression in various cancers using public data sets. USP11 expression was analyzed in various tumor types using the Oncomine database (www.oncomine.org) ${ }^{57}$ (GSE9348, ${ }^{58}$ GSE3189 ${ }^{59}$ ). USP11 expressions at various stages of colorectal cancer and melanoma were further confirmed using Gene Expression Omnibus (GEO) profiles (www.ncbi.nlm.nih.gov/ geoprofiles) (GSE4107,60 GSE18088, ${ }^{61}$ and GSE840162). The PROGgene database (www.compbio.iupui.edu/proggene) was used to identify the data sets for survival analysis and re-analyzed the public GEO data sets (www.ncbi.nlm.nih. gov/gds) (GSE28814). ${ }^{63}$ The melanoma survival rate was directly analyzed using the other GEO data set (GSE22153). ${ }^{64}$

Xenograft study. Approximately $2 \times 10^{6}$ HCT116 or $1 \times 10^{6}$ UACC- 62 stable cells expressing shGFP or shUSP11 were resuspended in $50 \mu \mathrm{l}$ PBS and $50 \mu \mathrm{l}$ Matrigel matrix (354234, BD Biosciences, Franklin Lakes, NJ, USA) and subcutaneously inoculated into 6-week-old female Balb/c nude mice (Narabiotech, Korea). One week after inoculation, mice bearing xenograft tumors were treated with TRAIL ( $5 \mathrm{mg} / \mathrm{kg}$, every 2 days, total eight treatments for HCT116 cells and total six treatment for UACC-62 cells) and BV6 $(10 \mathrm{mg} / \mathrm{kg}$, every 4 days, total four treatments for HCT116 cells and total three treatment for UACC-62 cells) by intraperitoneal (i.p.) injection. Tumor volume was measured using calipers and calculated according to the following formula: volume $=$ length $\times$ width $^{2} \times 0.5236$. All animal experiments were performed in specific pathogen-free facilities and in accordance with the Guidelines for The Institutional Animal Care and Use Committees of the Laboratory Animal Research Center at Yonsei University (Korea). To assess whether differences between groups were significant, a two-tailed MannWhitney test was performed using GraphPad Prism version 5.01 (GraphPad Software, La Jolla, CA, USA).

Statistics. Statistical significance was assessed by Student's $t$ test or a two-tailed Mann-Whitney test using GraphPad Prism version 5.01.

\section{Conflict of Interest}

The authors declare no conflict of interest.
Acknowledgements. This research was supported by a grant from the National Research Foundation of Korea (NRF) funded by the Korean government (MEST) (2010-0017787) (J Song), by a grant from the Korea Healthcare Technology R\&D Project, Ministry for Health \& Welfare Affairs, Republic of Korea (A121387) (J Song), and by a grant from the Basic Science Research Program through the National Research Foundation of Korea (NRF) funded by the Ministry of Education (2012R1A6A3A04040105) (EWL). DS, J Seo, MJ, and HKL were partly supported by a fellowship from the Brain Korea 21 (BK21) PLUS program.

1. Galluzzi L, Bravo-San Pedro JM, Vitale I, Aaronson SA, Abrams JM, Adam D et al. Essential versus accessory aspects of cell death: recommendations of the NCCD 2015. Cell Death Differ 2014; 22: 58-73.

2. Hartman ML, Czyz M. Anti-apoptotic proteins on guard of melanoma cell survival. Cancer Lett 2013; 331: 24-34.

3. Kvansakul M, Hinds MG. The structural biology of BH3-only proteins. Methods Enzymol 2014; 544: 49-74.

4. Silke J, Vucic D. IAP family of cell death and signaling regulators. Methods Enzymol 2014; 545: $35-65$.

5. Fulda S, Vucic D. Targeting IAP proteins for therapeutic intervention in cancer. Nat Rev Drug Discov 2012; 11: 109-124.

6. Gyrd-Hansen M, Meier P. IAPs: from caspase inhibitors to modulators of NF-kappaB, inflammation and cancer. Nat Rev Cancer 2010; 10: 561-574.

7. Lee EW, Seo J, Jeong M, Lee S, Song J. The roles of FADD in extrinsic apoptosis and necroptosis. BMB Rep 2012; 45: 496-508.

8. Bertrand MJ, Milutinovic S, Dickson KM, Ho WC, Boudreault A, Durkin J et al. clAP1 and cIAP2 facilitate cancer cell survival by functioning as E3 ligases that promote RIP1 ubiquitination. Mol Cell 2008; 30: 689-700.

9. Feoktistova M, Geserick P, Kellert B, Dimitrova DP, Langlais C, Hupe M et al. clAPs block Ripoptosome formation, a RIP1/caspase-8 containing intracellular cell death complex differentially regulated by cFLIP isoforms. Mol Cell 2011; 43: 449-463.

10. Tenev T, Bianchi K, Darding M, Broemer M, Langlais C, Wallberg F et al. The Ripoptosome, a signaling platform that assembles in response to genotoxic stress and loss of IAPs. Mol Cell 2011; 43: 432-448.

11. Geserick P, Hupe M, Moulin M, Wong WW, Feoktistova M, Kellert B et al. Cellular IAPs inhibit a cryptic CD95-induced cell death by limiting RIP1 kinase recruitment. J Cell Biol 2009; 187: 1037-1054.

12. Schilling R, Geserick P, Leverkus M. Characterization of the ripoptosome and its components: implications for anti-inflammatory and cancer t. Methods Enzymol 2014; 545: $83-102$

13. Vandenabeele $P$, Bertrand MJ. The role of the IAP E3 ubiquitin ligases in regulating pattern-recognition receptor signalling. Nat Rev Immunol 2012; 12: 833-844.

14. Bai L, Smith DC, Wang S. Small-molecule SMAC mimetics as new cancer therapeutics. Pharmacol Ther 2014; 144: 82-95.

15. Vucic D, Deshayes K, Ackerly H, Pisabarro MT, Kadkhodayan S, Fairbrother WJ et al. SMAC negatively regulates the anti-apoptotic activity of melanoma inhibitor of apoptosis (ML-IAP). J Biol Chem 2002; 277: 12275-12279.

16. Fulda S, Wick W, Weller M, Debatin KM. Smac agonists sensitize for Apo2L/TRAILor anticancer drug-induced apoptosis and induce regression of malignant glioma in vivo. Nat Med 2002; 8: 808-815

17. Varfolomeev E, Blankenship JW, Wayson SM, Fedorova AV, Kayagaki N, Garg P et al. IAP antagonists induce autoubiquitination of C-IAPs, NF-kappaB activation, and TNFalphadependent apoptosis. Cell 2007; 131: 669-681.

18. Vince JE, Wong WW, Khan N, Feltham R, Chau D, Ahmed AU et al. IAP antagonists target CIAP1 to induce TNFalpha-dependent apoptosis. Cell 2007; 131: 682-693.

19. Petersen SL, Wang L, Yalcin-Chin A, Li L, Peyton M, Minna J et al. Autocrine TNFalpha signaling renders human cancer cells susceptible to Smac-mimetic-induced apoptosis. Cancer Cell 2007; 12: 445-456.

20. Mahoney DJ, Cheung HH, Mrad RL, Plenchette S, Simard C, Enwere E et al. Both cIAP1 and CIAP2 regulate TNFalpha-mediated NF-kappaB activation. Proc Natl Acad Sci USA 2008; 105: 11778-11783.

21. Varfolomeev E, Goncharov T, Fedorova AV, Dynek JN, Zobel K, Deshayes K et al. c-IAP1 and C-IAP2 are critical mediators of tumor necrosis factor alpha (TNFalpha)-induced NF-kappaB activation. J Biol Chem 2008; 283: 24295-24299.

22. Petersen SL, Peyton M, Minna JD, Wang X. Overcoming cancer cell resistance to Smac mimetic induced apoptosis by modulating cIAP-2 expression. Proc Natl Acad Sci USA 2010; 107: 11936-11941.

23. Feltham R, Bettjeman B, Budhidarmo R, Mace PD, Shirley S, Condon SM et al. Smac mimetics activate the E3 ligase activity of CIAP1 protein by promoting RING domain dimerization. J Biol Chem 2011; 286: 17015-17028.

24. Darding M, Feltham R, Tenev T, Bianchi K, Benetatos C, Silke J et al. Molecular determinants of Smac mimetic induced degradation of cIAP1 and cIAP2. Cell Death Differ 2011; 18: 1376-1386.

25. Mei Y, Hahn AA, Hu S, Yang X. The USP19 deubiquitinase regulates the stability of C-IAP1 and C-IAP2. J Biol Chem 2011; 286: 35380-35387. 
26. Goncharov T, Niessen K, de Almagro MC, Izrael-Tomasevic A, Fedorova AV, Varfolomeev E et al. OTUB1 modulates C-IAP1 stability to regulate signalling pathways. EMBO J 2013; 32 : 1103-1114.

27. Steinhart L, Belz K, Fulda S. Smac mimetic and demethylating agents synergistically trigger cell death in acute myeloid leukemia cells and overcome apoptosis resistance by inducing necroptosis. Cell Death Dis 2013; 4: e802.

28. Krepler C, Chunduru SK, Halloran MB, He X, Xiao M, Vultur A et al. The novel SMAC mimetic birinapant exhibits potent activity against human melanoma cells. Clin Cancer Res 2013; 19: 1784-1794.

29. Bai L, McEachern D, Yang CY, Lu J, Sun H, Wang S. LRIG1 modulates cancer cell sensitivity to Smac mimetics by regulating TNFalpha expression and receptor tyrosine kinase signaling. Cancer Res 2012; 72: 1229-1238.

30. Varfolomeev E, Moradi E, Dynek JN, Zha J, Fedorova AV, Deshayes K et al. Characterization of ML-IAP protein stability and physiological role in vivo. Biochem J 2012; 447: 427-436.

31. Muller-Sienerth N, Dietz L, Holtz P, Kapp M, Grigoleit GU, Schmuck C et al. SMAC mimetic BV6 induces cell death in monocytes and maturation of monocyte-derived dendritic cells. PLOS ONE 2011; 6: e21556.

32. Maas C, Tromp JM, van Laar J, Thijssen R, Elias JA, Malara A et al. CLL cells are resistant to smac mimetics because of an inability to form a ripoptosome complex. Cell Death Dis 2013; 4: e782.

33. Tchoghandjian A, Jennewein C, Eckhardt I, Rajalingam K, Fulda S. Identification of noncanonical NF-kappaB signaling as a critical mediator of Smac mimetic-stimulated migration and invasion of glioblastoma cells. Cell Death Dis 2013; 4: e564.

34. Burkhart RA, Peng Y, Norris ZA, Tholey RM, Talbott VA, Liang $Q$ et al. Mitoxantrone targets human ubiquitin-specific peptidase 11 (USP11) and is a potent inhibitor of pancreatic cancer cell survival. Mol Cancer Res 2013; 11: 901-911.

35. Yamaguchi T, Kimura J, Miki Y, Yoshida K. The deubiquitinating enzyme USP11 controls an IkappaB kinase alpha (IKKalpha)-p53 signaling pathway in response to tumor necrosis factor alpha (TNFalpha). J Biol Chem 2007; 282: 33943-33948.

36. Sun W, Tan X, Shi Y, Xu G, Mao R, Gu X et al. USP11 negatively regulates TNFalphainduced NF-kappaB activation by targeting on IkappaBalpha. Cell Signal 2010; 22: 386-394.

37. Lamb JA, Ventura JJ, Hess P, Flavell RA, Davis RJ. JunD mediates survival signaling by the JNK signal transduction pathway. Mol Cell 2003; 11: 1479-1489.

38. Passante E, Wurstle ML, Hellwig CT, Leverkus M, Rehm M. Systems analysis of apoptosis protein expression allows the case-specific prediction of cell death responsiveness of melanoma cells. Cell Death Differ 2013; 20: 1521-1531.

39. Moulin M, Anderton H, Voss AK, Thomas T, Wong WW, Bankovacki A et al. IAPs limit activation of RIP kinases by TNF receptor 1 during development. EMBO J 2012; 31: 1679-1691.

40. Cheung HH, Beug ST St, Jean M, Brewster A, Kelly NL, Wang S et al. Smac mimetic compounds potentiate interleukin-1beta-mediated cell death. J Biol Chem 2010; 285: 40612-40623.

41. Cohen S, Bruchim I, Graiver D, Evron Z, Oron-Karni V, Pasmanik-Chor M et al. Platinumresistance in ovarian cancer cells is mediated by $\mathrm{IL}-6$ secretion via the increased expression of its target clAP-2. J Mol Med (Berl) 2013; 91: 357-368.

42. Lu J, McEachern D, Sun H, Bai L, Peng Y, Qiu S et al. Therapeutic potential and molecular mechanism of a novel, potent, nonpeptide, Smac mimetic SM-164 in combination with TRAIL for cancer treatment. Mol Cancer Ther 2011; 10: 902-914.

43. Ziegler DS, Wright RD, Kesari S, Lemieux ME, Tran MA, Jain M et al. Resistance of human glioblastoma multiforme cells to growth factor inhibitors is overcome by blockade of inhibitor of apoptosis proteins. J Clin Invest 2008; 118: 3109-3122.

44. Carter BZ, Mak PY, Mak DH, Shi Y, Qiu Y, Bogenberger JM et al. Synergistic targeting of AML stem/progenitor cells with IAP antagonist birinapant and demethylating agents. J Natl Cancer Inst 2014; 106: djt440.
45. Collins R, Trowman R, Norman G, Light K, Birtle A, Fenwick E et al. A systematic review of the effectiveness of docetaxel and mitoxantrone for the treatment of metastatic hormonerefractory prostate cancer. Br J Cancer 2006; 95: 457-462.

46. Kroemer G, Galluzzi L, Kepp O, Zitvogel L. Immunogenic cell death in cancer therapy. Annu Rev Immunol 2013; 31: 51-72.

47. Schutz FA, Buzaid AC, Sartor O. Taxanes in the management of metastatic castrationresistant prostate cancer: Efficacy and management of toxicity. Crit Rev Oncol Hematol 2014; 91: 248-256.

48. Dhanasekaran DN, Reddy EP. JNK signaling in apoptosis. Oncogene 2008; 27: 6245-6251.

49. Sabapathy K. Role of the JNK pathway in human diseases. Prog Mol Biol Transl Sci 2012; 106: $145-169$.

50. Kuntzen C, Sonuc N, De Toni EN, Opelz C, Mucha SR, Gerbes AL et al. Inhibition of C-Jun-N-terminal-kinase sensitizes tumor cells to CD95-induced apoptosis and induces G2/M cell cycle arrest. Cancer Res 2005; 65: 6780-6788.

51. Liu J, Lin A. Role of JNK activation in apoptosis: a double-edged sword. Cell Res 2005; 15: 36-42.

52. Sowa ME, Bennett EJ, Gygi SP, Harper JW. Defining the human deubiquitinating enzyme interaction landscape. Cell 2009; 138: 389-403.

53. Camus S, Higgins M, Lane DP, Lain S. Differences in the ubiquitination of $p 53$ by Mdm2 and the HPV protein E6. FEBS letters 2003; 536: 220-224.

54. Lee EW, Kim JH, Ahn YH, Seo J, Ko A, Jeong M et al. Ubiquitination and degradation of the FADD adaptor protein regulate death receptor-mediated apoptosis and necroptosis. Nat Commun 2012; 3: 978.

55. Kim SH, Kim K, Kwagh JG, Dicker DT, Herlyn M, Rustgi AK et al. Death induction by recombinant native TRAIL and its prevention by a caspase 9 inhibitor in primary human esophageal epithelial cells. J Biol Chem 2004; 279: 40044-40052.

56. Lee EW, Lee MS, Camus S, Ghim J, Yang MR, Oh W et al. Differential regulation of p53 and p21 by MKRN1 E3 ligase controls cell cycle arrest and apoptosis. EMBO J 2009; 28 : 2100-2113.

57. Rhodes DR, Yu J, Shanker K, Deshpande N, Varambally R, Ghosh D et al. ONCOMINE: a cancer microarray database and integrated data-mining platform. Neoplasia 2004; 6: $1-6$.

58. Hong Y, Downey T, Eu KW, Koh PK, Cheah PY. A 'metastasis-prone' signature for earlystage mismatch-repair proficient sporadic colorectal cancer patients and its implications for possible therapeutics. Clin Exp Metastasis 2010; 27: 83-90.

59. Talantov D, Mazumder A, Yu JX, Briggs T, Jiang Y, Backus $J$ et al. Novel genes associated with malignant melanoma but not benign melanocytic lesions. Clin Cancer Res 2005; 11: 7234-7242.

60. Hong Y, Ho KS, Eu KW, Cheah PY. A susceptibility gene set for early onset colorectal cancer that integrates diverse signaling pathways: implication for tumorigenesis. Clin Cancer Res 2007; 13: 1107-1114.

61. Grone J, Lenze D, Jurinovic V, Hummel M, Seidel H, Leder G et al. Molecular profiles and clinical outcome of stage UICC II colon cancer patients. Int J Colorectal Dis 2011; 26: 847-858.

62. Xu L, Shen SS, Hoshida Y, Subramanian A, Ross K, Brunet JP et al. Gene expression changes in an animal melanoma model correlate with aggressiveness of human melanoma metastases. Mol Cancer Res 2008; 6: 760-769.

63. Loboda A, Nebozhyn MV, Watters JW, Buser CA, Shaw PM, Huang PS et al. EMT is the dominant program in human colon cancer. BMC Med Genomics 2011; 4: 9.

64. Jonsson G, Busch C, Knappskog S, Geisler J, Miletic H, Ringner M et al. Gene expression profiling-based identification of molecular subtypes in stage IV melanomas with different clinical outcome. Clin Cancer Res 2010; 16: 3356-3367.

\section{Supplementary Information accompanies this paper on Cell Death and Differentiation website (http://www.nature.com/cdd)}

